\title{
Iron Force Constants of Bridgmanite at High Pressure: Implications for Iron Isotope Fractionation in the Deep Mantle
}

Wenzhong Wang ${ }^{1,2^{*}}$, Jiachao Liu $^{3,4}$, Hong Yang ${ }^{5 \dagger}$, Susannah M. Dorfman ${ }^{4, *}$, Mingda $\mathrm{Lv}^{4}$, Jie $\mathrm{Li}^{6}$, Feng Zhu ${ }^{6}$, Jiyong Zhao ${ }^{7}$, Michael Y. Hu${ }^{7}$, Wenli Bi ${ }^{7,8}$, Ercan E. Alp ${ }^{7}$, Yuming Xiao ${ }^{9}$, Zhongqing $\mathrm{Wu}^{1,}$, , Jung-Fu $\mathrm{Lin}^{3,}{ }^{*}$

${ }^{1}$ Laboratory of Seismology and Physics of Earth's Interior, School of Earth and Space Sciences, University of Science and Technology of China, Hefei, China;

${ }^{2}$ Department of Earth Sciences, University College London, Gower Street, London WC1E 6BT, UK;

${ }^{3}$ Department of Geological Sciences, Jackson School of Geosciences, The University of Texas at Austin, Austin, Texas 78712, USA;

${ }^{4}$ Department of Earth and Environmental Sciences, Michigan State University, MI 48824, USA

${ }^{5}$ Center for High Pressure Science and Technology Advanced Research (HPSTAR), Pudong, Shanghai 201203, China;

${ }^{6}$ Department of Earth and Environmental Sciences, University of Michigan, MI 48109, USA;

${ }^{7}$ Advanced Photon Source, Argonne National Laboratory, Argonne, Illinois 60439, USA;

${ }^{8}$ Department of Geology, University of Illinois at Urbana-Champaign, Urbana, Illinois 61801, USA;

${ }^{9}$ High Pressure Collaborative Access Team (HPCAT), X-Ray Science Division, Argonne National Lab, Argonne, Illinois 60439, USA;

${ }^{\dagger}$ Now at Department of Geological Sciences, Stanford University, Stanford, CA 94305, USA.

${ }^{*}$ J.C. Liu and W.Z. Wang contributed equally to this work.

Corresponding authors: W. Wang (wenzhong.wang@ucl.ac.uk), S. M. Dorfman (dorfman3@msu.edu), J.F. Lin (afu@jsg.utexas.edu), or Zhongqing Wu (wuzq10@ustc.edu.cn) 


\section{Abstract}

The isotopic compositions of iron in major mantle minerals may record chemical

3 exchange between deep-Earth reservoirs as a result of early differentiation and ongoing 4 plate tectonics processes. Bridgmanite (Bdg), the most abundant mineral in the Earth's 5 lower mantle, can incorporate not only Al but also Fe with different oxidation states 6 and spin states, which in turn can influence the distribution of Fe isotopes between Bdg and ferropericlase (Fp) and between the lower mantle and the core. In this study, we combined first-principles calculations with high-pressure nuclear resonant inelastic Xray scattering measurements to evaluate the effects of Fe site occupancy, valence, and spin states at lower-mantle conditions on the reduced Fe partition function ratio $(\beta$ -

11 factor) of Bdg. Our results show that the spin transition of octahedral-site (B-site) $\mathrm{Fe}^{3+}$

12 in Bdg under mid-lower-mantle conditions generates a $+0.09 \%$ increase in its $\beta$-factor, 13 which is the most significant effect compared to Fe site occupancy and valence. $\mathrm{Fe}^{2+}$ 14 bearing $\mathrm{Bdg}$ varieties have smaller $\beta$-factor relative to $\mathrm{Fe}^{3+}$-bearing varieties, especially 15 those containing B-site $\mathrm{Fe}^{3+}$. Our models suggest that $\mathrm{Fe}$ isotopic fractionation between 16 Bdg and Fp is only significant in the lowermost mantle due to the occurrence of low17 spin $\mathrm{Fe}^{2+}$ in Fp. Assuming early segregation of an iron core from a deep magma ocean, 18 we find that neither core formation nor magma ocean crystallization would have 19 resulted in resolvable $\mathrm{Fe}$ isotope fractionation. In contrast, $\mathrm{Fe}$ isotopic fractionation 20 between low-spin $\mathrm{Fe}^{3+}$-bearing $\mathrm{Bdg} / \mathrm{Fe}^{2+}$-bearing $\mathrm{Fp}$ and metallic iron at the core21 mantle boundary may have enriched the lowermost mantle in heavy Fe isotopes by up 22 to $+0.20 \%$.

23 Keywords: Fe isotopic fractionation, bridgmanite, spin transition, nuclear resonant 24 spectroscopy, first-principles calculations

\section{Introduction}

Iron, the most abundant element in the Earth by weight, is the dominant component of the core and the only major transition metal in the mantle. Signatures of planetary $30\left(\delta^{\mathrm{i}} \mathrm{Fe}=\left(\left({ }^{\mathrm{i}} \mathrm{Fe} /{ }^{54} \mathrm{Fe}\right)_{\text {sample }} /\left({ }^{\mathrm{i}} \mathrm{Fe} /{ }^{54} \mathrm{Fe}\right)_{\text {standard }}-1\right) * 1000 \%\right.$ o, $\mathrm{i}=56$ or 57$)$ in the Earth's crust, 31 mantle, and core (Poitrasson et al., 2009; Polyakov, 2009; Poitrasson et al., 2013; Rubie 
et al., 2015; Sossi et al., 2016; Elardo and Shahar, 2017; Teng et al., 2017). Terrestrial mid-ocean ridge basalts (MORBs) exhibit strikingly high $\delta^{56} \mathrm{Fe}$ of $0.105 \pm 0.006 \%$

34 (Teng et al., 2013) relative to chondritic values, suggesting the enrichment of heavy Fe 35 isotopes in the Earth's upper mantle. Several hypotheses have been proposed to explain the Fe isotope signatures in the mantle, including evaporation loss of light iron isotopes during Earth's accretion (Poitrasson et al., 2004; Poitrasson, 2007), Fe isotopic fractionation during core formation (Polyakov, 2009; Elardo and Shahar, 2017), and mantle partial melting (Teng et al., 2008; Dauphas et al., 2014). Evaluation of the effects of these processes on the $\mathrm{Fe}$ isotope composition requires $\mathrm{Fe}$ equilibrium isotopic fractionation factors $\left(\Delta^{56} \mathrm{Fe}\right)$ between major Fe-bearing mantle and core minerals/melts under pressure-temperature (P-T) conditions relevant to the early and current Earth's interior.

Bridgmanite (Bdg) and ferropericlase (Fp) are the most abundant Fe-bearing minerals in the lower mantle. As such, the reduced Fe partition function ratios ( $\beta$-factors) for Bdg, Fp, and iron-light element alloys are key parameters for modelling Fe isotopic composition (Schauble, 2011; Huang et al., 2013; Huang et al., 2014; Wu et al., 2015a;

51 Shahar et al., 2016; Liu et al., 2017; Yang et al., 2019). In addition, Fe in both Bdg and 52 Fp have been found to undergo spin transitions under mid-lower-mantle conditions (e.g., 53 Lin et al., 2013; Liu et al., 2018), which can significantly change their electronic 54 structures (Hsu et al., 2011), Fe bond stiffnesses (Polyakov, 2009; Rustad and Yin, 2009; 55 Lin et al., 2013), and hence presumably influence Fe isotope fractionation. A recent work conducted by Yang et al. (2019) observed a significant increase in the $\beta$-factor of Fp across its $\mathrm{Fe}^{2+}$ spin transition in the octahedral site at $\sim 60 \mathrm{GPa}$ and $300 \mathrm{~K}$, whereas the $\beta$-factor of $\mathrm{Bdg}$ remains unchanged with increasing pressure likely due to lattice distortion. Additionally, the effects of light elements on the $\beta$-factor of metallic Fe alloy at high P-T conditions will also affect our understanding of deep-Earth iron isotope distribution (Chen et al., 2014; Shahar et al., 2016; Liu et al., 2017; Chen et al., 2018). 
considering the two possible crystallographic sites can accommodate Fe with different valences and spin states as well as other minor cations like Al. The individual contribution of each lattice site to the mean force constant of the phase cannot be uniquely determined in high-pressure nuclear resonant inelastic X-ray scattering measurements (e.g., Yang et al. 2019) which yields only the total average inelastic scattering behavior of the sample. The Bdg structure accommodates Fe in both the larger pseudo-dodecahedral (8-fold) A-site and the smaller octahedral (6-fold) B-site (Lin et al., 2013). While $\mathrm{Fe}^{2+}$ can only reside in the large A-site, $\mathrm{Fe}^{3+}$ can enter both sites through different proposed substitution mechanisms such as $\mathrm{Mg}^{2+} \mathrm{A}^{+} \mathrm{Si}^{4+} \mathrm{B} \rightarrow$ $\mathrm{Fe}^{3+} \mathrm{A}^{+} \mathrm{Fe}^{3+}{ }_{\mathrm{B}}$ and $\mathrm{Mg}^{2+}{ }_{\mathrm{A}}+\mathrm{Si}^{4+}{ }_{\mathrm{B}} \rightarrow \mathrm{Fe}^{3+}{ }_{\mathrm{A}}+\mathrm{Al}^{3+}{ }_{\mathrm{B}}$ (Frost et al., 2004; Liu et al., 2015). Only $\mathrm{Fe}^{3+}$ in the Bdg B-site is expected to undergo a high-spin (HS) to low-spin (LS) transition at pressures corresponding to mid-mantle depths, while A-site $\mathrm{Fe}^{2+}$ and $\mathrm{Fe}^{3+}$ experience lattice distortion but both valence states maintain HS state throughout the lower mantle (Catalli et al., 2010; Hsu et al., 2011; Mao et al., 2015; Shukla and Wentzcovitch, 2016; Fu et al., 2018b; Liu et al., 2018).

Many previous studies have argued that iron exists predominantly as $\mathrm{Fe}^{3+}$ in $\mathrm{Bdg}$, on the basis of increased stability of $\mathrm{Fe}^{3+}$ in Bdg structure at lower-mantle-relevant oxygen fugacity conditions (Catalli et al., 2010; Frost et al., 2004; Frost and 81 McCammon, 2008; Li et al., 2006; Marquardt et al., 2009; McCammon, 1997). Furthermore, a recent work (Armstrong et al., 2019) also found that $\mathrm{Fe}^{2+}$ in a deep magma ocean would disproportionate to $\mathrm{Fe}^{3+}$ plus metallic iron at high pressures. As such, consequent segregation of precipitated iron metal from the lower mantle into the core could leave the Bdg enriched in $\mathrm{Fe}^{3+}$ after magma ocean crystallization. In addition, experimental studies (Frost et al., 2004; Shim et al., 2017; Andrault et al., 2018) also reporeted $\mathrm{Fe}^{3+}$-rich $\mathrm{Bdg}$ in equilibrium with iron metal due to the disproportionation of $\mathrm{Fe}^{2+}$. Although recent experimental and theoretical studies have reported the $\beta$-factors of several Bdg compositions (Shahar et al., 2016; Yang et al., 2019), none of the studies have examined the effect of $\mathrm{Fe}^{3+}$ in the $\mathrm{B}$-site, precluding the evaluation of the influence

91 of the $\mathrm{B}$-site $\mathrm{Fe}^{3+}$ spin transition on the $\beta$-factors of $\mathrm{Bdg}$. In addition to $\mathrm{Fe}^{3+}, \mathrm{Al}^{3+}$ can 92 also enter $\mathrm{A}$ and $\mathrm{B}$ sites in Bdg through the coupled substitution mechanism $\mathrm{Mg}^{2+} \mathrm{A}^{+}$ $93 \mathrm{Si}^{4+}{ }_{\mathrm{B}}=\left(\mathrm{Fe}^{3+}, \mathrm{Al}^{3+}\right)_{\mathrm{A}}+\left(\mathrm{Fe}^{3+}, \mathrm{Al}^{3+}\right)_{\mathrm{B}}$ (Frost et al., 2004; Liu et al., 2015; Shim et al., 
2017; Yang et al., 2019). As the radius of $\mathrm{Al}^{3+}$ is smaller than both A-site and B-site

$95 \mathrm{Fe}^{3+}$, it prefers to substitute into the smaller B-site and the content of B-site $\mathrm{Fe}^{3+}$ is

96 influenced by the $\mathrm{Fe}^{3+} / \mathrm{Al}$ ratio (Frost et al., 2004; Liu et al., 2015; Shim et al., 2017).

97 Thus, comparison of the $\beta$-factors between Al-bearing and Al-free Bdg is needed to reveal the effect of $\mathrm{Al}$ on the $\beta$-factor of $\mathrm{Bdg}$.

In this study, we determine the $\beta$-factors of $\left(\mathrm{Mg}_{0.5} \mathrm{Fe}^{3+}{ }_{0.5}\right)\left(\mathrm{Si}_{0.5} \mathrm{Fe}^{3+}{ }_{0.5}\right) \mathrm{O}_{3} \mathrm{Bdg}$ at mantle-relevant pressures by both nuclear resonant inelastic X-ray scattering (NRIXS) and the density functional theory (DFT) augmented by a Hubbard $U$ correction method. The spin transition of the B-site $\mathrm{Fe}^{3+}$ in $\left(\mathrm{Mg}_{0.5} \mathrm{Fe}^{3+}{ }_{0.5}\right)\left(\mathrm{Si}_{0.5} \mathrm{Fe}^{3+}{ }_{0.5}\right) \mathrm{O}_{3} \mathrm{Bdg}$ at 43-50 GPa has been inferred from X-ray diffraction, X-ray emission and electrical conductivity measurements (Liu et al., 2018). This sample thus offers the possibility to unambiguously determine the influence of the $\mathrm{B}$-site $\mathrm{Fe}^{3+}$ spin transition on its $\beta$-factor. In addition, the pressure- and temperature-dependent $\beta$-factors of $\mathrm{Fe}$ in four other bridgmanite compositions were calculated by the DFT $+U$ method, including $\mathrm{Fe}^{3+}$ - and $\mathrm{Al}^{3+}$-bearing Bdg, $\left(\mathrm{Mg}_{0.9375} \mathrm{Fe}^{3+}{ }_{0.0625}\right)\left(\mathrm{Si}_{0.9375} \mathrm{Al}_{0.0625}\right) \mathrm{O}_{3},\left(\mathrm{Mg}_{0.75} \mathrm{Fe}^{3+}{ }_{0.25}\right)\left(\mathrm{Si}_{0.75} \mathrm{Al}_{0.25}\right) \mathrm{O}_{3}$, and $\mathrm{Fe}^{2+}$-bearing $\mathrm{Bdg}$, $\left(\mathrm{Mg}_{0.75} \mathrm{Fe}^{2+}{ }_{0.25}\right) \mathrm{SiO}_{3}$ and $\left(\mathrm{Mg}_{0.5} \mathrm{Fe}^{2+}{ }_{0.5}\right) \mathrm{SiO}_{3}$. The calculated results are used to constrain the effects of valence, spin states, and site occupancies of $\mathrm{Fe}$ in $\mathrm{Bdg}$ on its $\beta$-factor at high pressure and temperature. To assess how Fe isotopes distribute between Bdg and Fp in the lower mantle, our results are further used to model the depth-dependence of $\Delta^{56} \mathrm{Fe}_{\mathrm{Bdg}}$-Fp for various bulk mantle compositions. Finally, we estimate the effect of Fe species in Bdg, Fp, and metallic iron-light element alloys on the scale of $\mathrm{Fe}$ isotopic fractionation between the lower mantle and the core.

\section{Materials and Methods}

\subsection{Bridgmanite sample synthesis and DAC preparation}

${ }^{57} \mathrm{Fe}$-enriched $\left(\mathrm{Mg}_{0.46} \mathrm{Fe}^{3+}{ }_{0.53}\right)\left(\mathrm{Si}_{0.49} \mathrm{Fe}^{3+}{ }_{0.51}\right) \mathrm{O}_{3} \mathrm{Bdg}$ sample was synthesized as in Liu et al. (2018). Briefly, fine-powdered 94.45\% ${ }^{57} \mathrm{Fe}$-enriched $\mathrm{Fe}_{2} \mathrm{O}_{3}$ (Cambridge Isotope Laboratories) was homogeneously mixed with $\mathrm{MgO}$ and $\mathrm{SiO}_{2}$ in 1:1:1 molar ratios. $\left(\mathrm{Mg}_{0.46} \mathrm{Fe}^{3+}{ }_{0.53}\right)\left(\mathrm{Si}_{0.49} \mathrm{Fe}^{3+}{ }_{0.51}\right) \mathrm{O}_{3}$ akimotoite was recovered from the multi-anvil synthesis at $24 \mathrm{GPa}$ and $1873 \mathrm{~K}$ for $\sim 9$ hours. The sample used in this study is from the same multi-anvil press synthesis used in Liu et al. (2018) and (Dorfman et al. (2020). 
125 Multiple experimental runs confirmed via refinement of X-ray diffraction data that this 126 akimotoite reproducibly and reversibly transforms to Bdg at $\sim 24 \mathrm{GPa}$ and $300 \mathrm{~K}$ 127 (Dorfman et al. 2018), therefore the NRIXS measurements collected at $32.5 \mathrm{GPa}$ and 128 above are within the stability field of Bdg. Synchrotron Mössbauer spectroscopy (Liu 129 et al., 2018) and conventional Mössbauer spectroscopy (Dorfman et al., 2020) confirm

130 that all $\mathrm{Fe}$ in this sample is $\mathrm{Fe}^{3+}$, which enters Bdg structure through coupled 131 substitution $\left(\mathrm{Mg}^{2+} \mathrm{A}+\mathrm{Si}^{4+}{ }_{\mathrm{B}}=\mathrm{Fe}^{3+}{ }_{\mathrm{A}}+\mathrm{Fe}^{3+}{ }_{\mathrm{B}}\right)$.

132 A panoramic diamond anvil cell (DAC) equipped with a pair of $300-\mu \mathrm{m}$ culet 133 diamonds was used for NRIXS measurements up to $60.9 \mathrm{GPa}$. NRIXS signals at higher 134 pressures were measured from a three-opening panoramic DAC equipped with a pair 135 of $150-\mu \mathrm{m}$ culet diamonds and three APD detectors at Argonne National Laboratory.

136 To increase the signal-to-background ratio, the upstream diamond was partially 137 perforated to reduce scattering of the incoming X-ray beam. X-ray transparent, high138 purity Be gaskets $3 \mathrm{~mm}$ in diameter with cubic boron nitride (c-BN) inserts were used 139 to support sample chamber and provide windows for NRIXS signal collection. The c140 BN insert was preindented to $\sim 30-\mu \mathrm{m}$ thickness before a $\sim 70-\mu \mathrm{m}$-diameter sample 141 chamber was drilled on its center. In the sample chamber, $\sim 15 \times 15 \times 10 \mu \mathrm{m}^{3}$ sample was 142 sandwiched between two layers of $\sim 5-\mu \mathrm{m}$-thick $\mathrm{NaCl}$ pressure medium. 5- $\mu \mathrm{m}$ ruby 143 spheres next to the samples were used as pressure gauge (Mao et al., 1986) below $\sim 70$ 144 GPa. For higher pressure experiments, pressures were determined from the edge of the 145 diamond Raman peak measured at the sample position (Akahama and Kawamura, 146 2010).

\subsection{NRIXS measurements and data analysis}

NRIXS measurements for ${ }^{57} \mathrm{Fe}$-enriched $\left(\mathrm{Mg}_{0.46} \mathrm{Fe}^{3+}{ }_{0.53}\right)\left(\mathrm{Si}_{0.49} \mathrm{Fe}^{3+}{ }_{0.51}\right) \mathrm{O}_{3}$ Bdg 150 sample (Fig. 1) at 32.5-60.9 GPa and 71.4-101.4 GPa were conducted at beamlines 16151 ID-D and 3-ID-B of the Advanced Photon Source, Argonne National Laboratory, 152 respectively. At both beamlines the incident X-ray beam was focused to $\sim 10 \mu \mathrm{m}$ in 153 diameter on the sample in a DAC. NRIXS spectra were collected by avalanche photo 154 diode (APD) detectors attached to DACs, respectively. Each NRIXS spectrum was 155 generated by scanning energy near the ${ }^{57} \mathrm{Fe}$ nuclear transition energy of $14.4125 \mathrm{keV}$ 
156 by tuning a high-resolution monochromator. The energy resolution was $1 \mathrm{meV}$ with a 157 step size of $0.334 \mathrm{meV}$ at beamline 3-IDB and $2 \mathrm{meV}$ with a step size of $0.67 \mathrm{meV}$ at 158 beamline 16-ID-D. Collection times were 3-5 s/step, for a total of $\sim 1$ hour per NRIXS spectrum. At each pressure, 15-40 NRIXS spectra were collected and summed to make

160 sufficient signal-to-noise ratio (Fig. 1). The spectra at pressure below $60.9 \mathrm{GPa}$ were 161 collected at 16 IDD while others were collected at 3-ID-B. The ranges of scanned 162 energy for each spectrum can be found in Fig. 1. These wide energy ranges are critical 163 for capturing the multi-phonon contributions to PDOS and reliable background removal 164 (Dauphas et al., 2018).

NRIXS data were processed using the software package SciPhon (Dauphas et al., 166 2018). First the energy resolution function of the incident $X$-ray was used to 167 deconvolute the NRIXS spectrum and a linear background based on high-energy 168 (beyond $\pm 100 \mathrm{meV}$ ) part of the spectrum was subtracted. The NRIXS spectrum was 169 then used to derive the phonon density of states (PDOS) of iron atoms in the lattice. 170 This derivation uses the harmonic approximation, which assumes the lattice potentials 171 are proportional to atomic displacement squared.

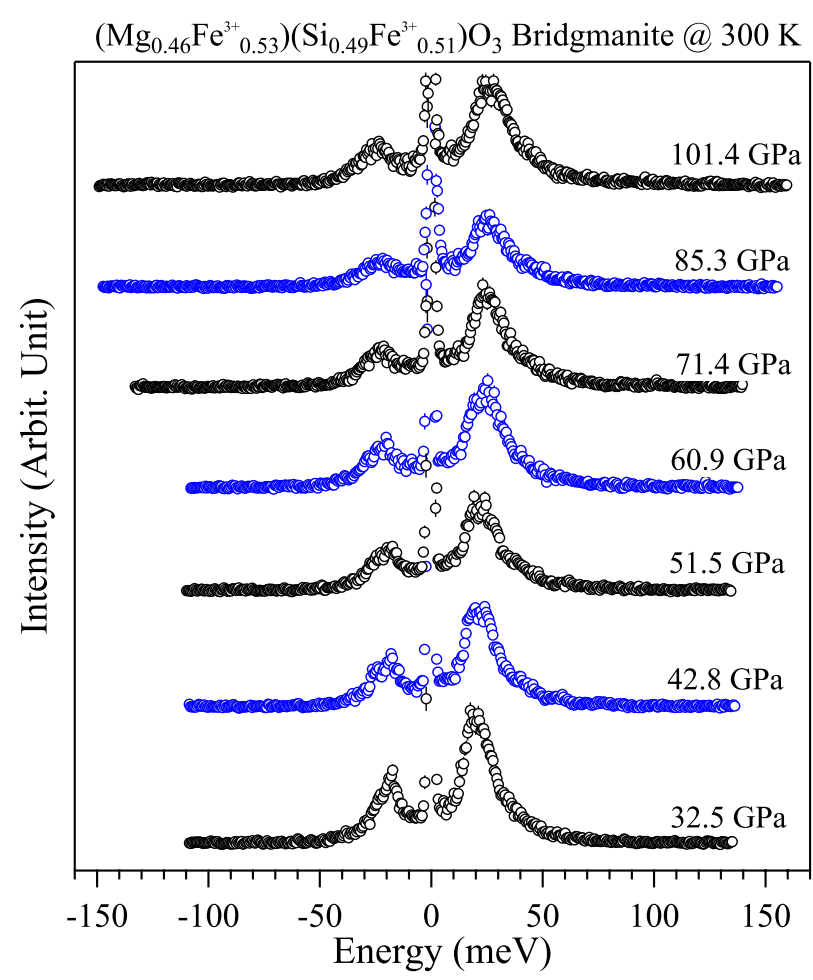

173 Figure 1. NRIXS spectra of ${ }^{57} \mathrm{Fe}$-enriched $\left(\mathrm{Mg}_{0.5} \mathrm{Fe}^{3+}{ }_{0.5}\right)\left(\mathrm{Si}_{0.5} \mathrm{Fe}^{3+}{ }_{0.5}\right) \mathrm{O}_{3}$ bridgmanite sample at $174300 \mathrm{~K}$ and high pressures. The peak at $0 \mathrm{meV}$ corresponds to the recoilless elastic scattering, 
while the other inelastic peaks origin from either phonon creation $(E>0)$ or annihilation $(E<$

$1760)$.

\subsection{First-principles calculations}

All calculations were performed using the Quantum Espresso package (Giannozzi et al., 2009) based on density functional theory (DFT), plane wave, and pseudopotential.

181 The local density approximation (LDA) was adopted for the exchange correlation 182 function. The energy cutoff for plane waves was $70 \mathrm{Ry}$. The pseudopotentials for $\mathrm{Mg}$, $183 \mathrm{Si}, \mathrm{O}$, and $\mathrm{Al}$ were well described in our previous studies (Huang et al., 2013; Huang et 184 al., 2014; Wu et al., 2015a; Wang and Wu, 2018). The pseudopotential for Fe was generated using the Vanderbilt method (Vanderbilt, 1990) with a valence configuration of $3 s^{2} 3 p^{6} 3 d^{6.5} 4 s^{1} 4 p^{0}$ and a cutoff radius of 1.8 Bohr. These pseudopotentials have been successfully applied to predict the structures, vibrational properties, elasticity, and equilibrium isotope fractionation of mantle silicate minerals including bridgmanite in our previous studies (Núñez Valdez et al., 2012; Núñez-Valdez et al., 2013; Huang et al., 2013; Huang et al., 2014; Feng et al., 2014; Wu et al., 2015b; Shukla et al., 2015;

191 Wang et al., 2017a; Wang et al., 2017b; Qian et al., 2018; Wang et al., 2019a). To

192 address the large on-site Coulomb interactions among the localized electrons ( $\mathrm{Fe} 3 \mathrm{~d}$ 193 electrons) (Anisimov et al., 1991), we introduced a Hubbard $U$ correction to the LDA $194(\mathrm{LDA}+U)$ for all DFT calculations. $U$ values for $\mathrm{Fe}^{2+}$ and $\mathrm{Fe}^{3+}$ on $\mathrm{A}$ - and/or B- sites in 195 bridgmanite are obtained from previous work (Hsu et al., 2010; Hsu et al., 2011), in 196 which values were non-empirically determined using linear response method 197 (Cococcioni and de Gironcoli, 2005). The U values for A-site $\mathrm{Fe}^{2+}, \mathrm{A}$-site $\mathrm{HS} \mathrm{Fe}^{3+}$, B198 site $\mathrm{HS} \mathrm{Fe}^{3+}$, B-site LS $\mathrm{Fe}^{3+}$ are $3.1 \mathrm{eV}, 3.7 \mathrm{eV}, 3.3 \mathrm{eV}$, and $4.9 \mathrm{eV}$, respectively. The 199 LDA+U method has been widely and successfully applied to predict the physical and 200 chemical properties of Fe-bearing Bdg and Fp (Hsu et al., 2011; Wu et al., 2013; Shukla 201 and Wentzcovitch, 2016). For $\left(\mathrm{Mg}_{0.5} \mathrm{Fe}^{3+}{ }_{0.5}\right)\left(\mathrm{Si}_{0.5} \mathrm{Fe}^{3+}{ }_{0.5}\right) \mathrm{O}_{3}$ $202\left(\mathrm{Mg}_{0.9375} \mathrm{Fe}^{3+}{ }_{0.0625}\right)\left(\mathrm{Si}_{0.9375} \mathrm{Al}_{0.0625}\right) \mathrm{O}_{3}$, and $\left(\mathrm{Mg}_{0.75} \mathrm{Fe}^{3+}{ }_{0.25}\right)\left(\mathrm{Si}_{0.75} \mathrm{Al}_{0.25}\right) \mathrm{O}_{3}$ Bdg, we 203 consider only configurations with the nearest neighbor $\left[\mathrm{Fe}^{3+}\right]_{\mathrm{Mg}}-\left[\mathrm{Fe}^{3+} / \mathrm{Al}^{3+}\right]_{\mathrm{Si}}$ since they 204 are the lowest energy configurations (Hsu et al., 2011; Shukla and Wentzcovitch, 2016). 205 Crystal structures at variable pressures were optimized on a $6 \times 6 \times 4 \mathrm{k}$-point mesh, and 
206 vibrational density of states (VDOS) were calculated using the finite displacement 207 method as implemented in the code PHONOPYT (Togo and Tanaka, 2015). At static 208 conditions, the B-site $\mathrm{Fe}^{3+}$ undergoes a HS-LS transition at $\sim 52 \mathrm{GPa}$, consistent with 209 previous LDA+U calculations (Shukla and Wentzcovitch, 2016). This value is $\sim 8 \mathrm{GPa}$ 210 larger than the spin-transition pressure in $\left(\mathrm{Mg}_{0.875} \mathrm{Fe}^{3+}{ }_{0.125}\right)\left(\mathrm{Si}_{0.875} \mathrm{Fe}^{3+}{ }_{0.125}\right) \mathrm{O}_{3} \mathrm{Bdg}$ due 211 to the difference in $\mathrm{Fe}^{3+}$ content.

212 Reduced partition function ratios were computed from phonon frequencies 213 obtained from DFT calculations. The reduced partition function ratio $\beta_{\mathrm{A}}$ of the element $214 \mathrm{X}$ in phase $\mathrm{A}$, which represents the equilibrium isotope fractionation factor between the 215 phase $\mathrm{A}$ and an ideal gas of $\mathrm{X}$ atoms, can be expressed within the quasi-harmonic 216 approximation as:

$$
\beta_{A}=\frac{Q_{h}}{Q_{l}}=\prod_{i}^{3 N} \frac{u_{i h}}{u_{i l}} \frac{e^{-\frac{1}{2} u_{i h}}}{1-e^{-u_{i h}}} \frac{1-e^{-u_{i l}}}{e^{-\frac{1}{2} u_{i l}}}
$$

218 where $h$ and $l$ refer to the heavy and light isotopes respectively; $i$ is a running index for 219 the vibrational frequency, and $N$ is the number of atoms in the unit cell. $Q_{h}$ and $Q_{l}$ 220 represent the vibrational partition function for the heavy and light isotopes, respectively. 221 Parameters $u_{i h}$ and $u_{i l}$ are defined as:

$$
u_{\text {ih or } i l}=\hbar \omega_{\text {ih or } i l} / k_{B} T
$$

223 Parameters $\hbar$ and $k_{B}$ are the reduced Planck and Boltzmann constants, respectively; $224 T$ is temperature in Kelvin, and $\omega_{\text {ih } \text { or } i l}$ is the vibrational frequency of the $i^{\text {th }}$ mode.

225 Notably, $\beta$ in Eq. (1) is volume-dependent as phonon frequencies from the DFT $+U$ 226 calculations are a function of volume. In order to express $\beta$ as a function of pressure $(P)$ 227 and temperature $(T)$, we calculated the equation of state $V(P, T)$ from the Helmholtz 228 free energy, which can be written within the quasi-harmonic approximation as:

$$
F(V, T)=U(V)+\frac{1}{2} \sum_{q, m} \hbar \omega_{q, m}(V)+k_{B} T \sum_{q, m} \ln \left(1-\exp \left(-\frac{\hbar \omega_{q, m}(V)}{k_{B} T}\right)\right.
$$

230 where $q$ is a wave vector in the Brillouin zone and $m$ is a running index of phonon mode. 231 The first, second, and third terms in Eq. (3) correspond to the static, zero-point, and 232 vibrational energy contributions, respectively. The calculated Helmholtz free energy 233 versus volume was fitted by the third-order Birch-Murnaghan finite strain equation of 234 state. Consequently, the pressure- and temperature-dependent $\beta$ can be derived and the 235 equilibrium isotope fractionation factor between two Phases A and B can be obtained 
in per mil (\%o) as:

$$
\Delta_{A-B} \approx 10^{3} \ln \alpha_{A-B}=10^{3} \ln \beta_{A}-10^{3} \ln \beta_{B}
$$

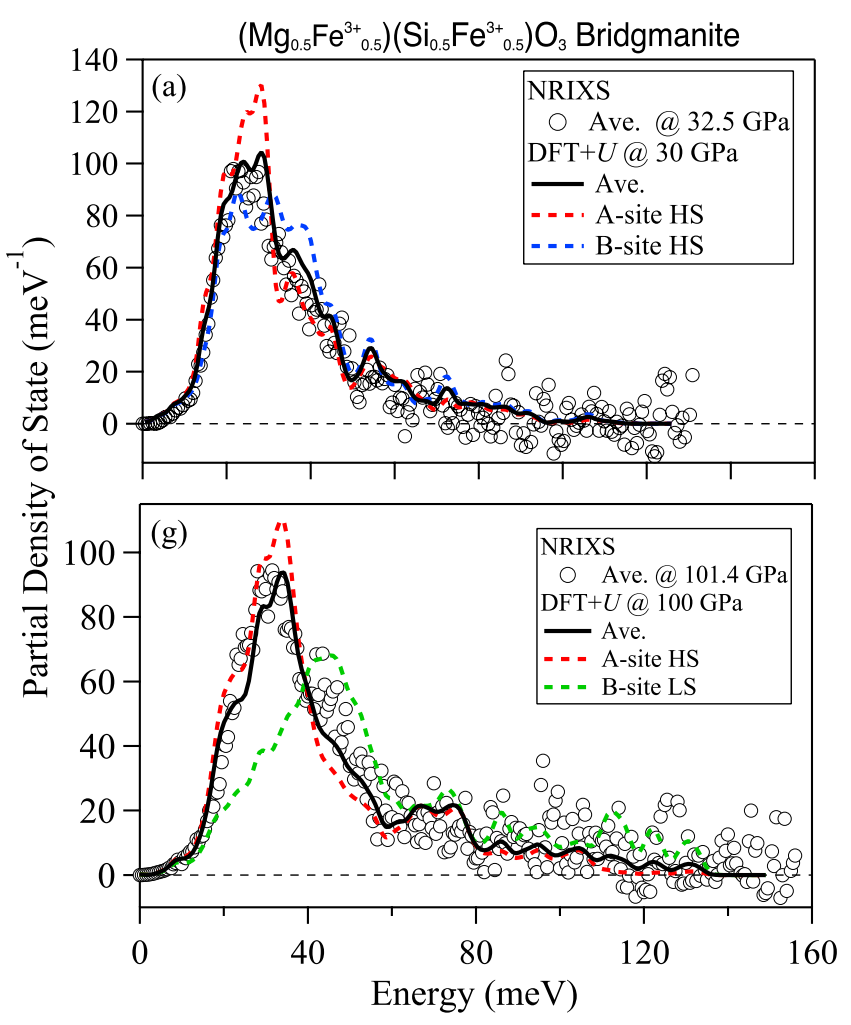

240 Figure 2. Representative partial phonon density of states (PDOS) of $\mathrm{Fe}^{3+}$ in

$241\left(\mathrm{Mg}_{0.5} \mathrm{Fe}^{3+}{ }_{0.5}\right)\left(\mathrm{Si}_{0.5} \mathrm{Fe}^{3+}{ }_{0.5}\right) \mathrm{O}_{3}$ bridgmanite derived from both NRIXS measurements and $\mathrm{DFT}+U$

242 calculations. The open circles are the averaged PDOS of all $\mathrm{Fe}$ ions in the Bdg measured by 243 NRIXS; (a): $32.5 \mathrm{GPa}$, (b): 101.4 GPa. The blue dotted, red dashed, and green dashed curves 244 are the PDOS of A-site $\mathrm{HS} \mathrm{Fe}^{3+}, \mathrm{B}$-site $\mathrm{HS} \mathrm{Fe}^{3+}$ and B-site $\mathrm{LS} \mathrm{Fe}^{3+}$ from DFT $+U$ calculations, 245 respectively. The black curves represent best-fit linear mixing model between $\mathrm{DFT}+U$ 246 calculated PDOS of the A-site and B-site $\mathrm{Fe}^{3+}$. The best-fit ratio of the weights is 50:50 for A247 site and B-site HS Fe ${ }^{3+}$ PDOS in (a); the ratio changes to 70:30 for A-site HS and B-site LS $248 \mathrm{Fe}^{3+}$ PODS in (b).

\section{3. Results}

\section{$251 \quad 3.1$ Partial phonon density of state of $\mathrm{Fe}$ in bridgmanite}

252 For all pressures investigated, the calculated PDOS of Fe agree well with 253 experimental PDOS (Fig. 2 and S1). Theoretical calculations provide the PDOS of the 254 A-site and B-site $\mathrm{Fe}^{3+}$ individually, while the PDOS of $\mathrm{Fe}$ in 
$255\left(\mathrm{Mg}_{0.5} \mathrm{Fe}^{3+}{ }_{0.5}\right)\left(\mathrm{Si}_{0.5} \mathrm{Fe}^{3+}{ }_{0.5}\right) \mathrm{O}_{3}$ Bdg derived from NRIXS measurements is a sum of 256 contributions from both A-site and $\mathrm{B}$-site $\mathrm{Fe}^{3+}$. Comparisons between experimental 257 observations of the PDOS, predictions for individual sites, and best-fit weighted average of calculated PDOS are shown for two representative pressures (Fig. 2). In theory, the ratio of $\mathrm{A}$-site and $\mathrm{B}$-site $\mathrm{Fe}^{3+}$ contributions to the final PDOS is the 260 concentration ratio, 50:50. At $\sim 30 \mathrm{GPa}$, the dominant peaks in the predicted PDOS of 261 the A-site and B-site $\mathrm{HS} \mathrm{Fe}^{3+}$ are located at $\sim 17-31 \mathrm{meV}$ and 17-43 meV, respectively 262 (Fig. 2a). A 50-50 average of these calculated PDOS for A-site $\mathrm{HS} \mathrm{Fe}^{3+}$ and B-site HS $263 \mathrm{Fe}^{3+}$ by DFT $+U$ matches well with the experimental PDOS (Fig. 2a). This is in good agreement with the X-ray emission spectroscopy analysis that Bdg is $100 \% \mathrm{HS}$ at this pressure (Liu et al., 2018). At $\sim 100 \mathrm{GPa}, \mathrm{DFT}+U$ calculations indicate that the transition of B-site $\mathrm{HS} \mathrm{Fe}^{3+}$ to LS state significantly change the PDOS: compared with the B-site $\mathrm{HS} \mathrm{Fe}^{3+}$, the predicted PDOS of the B-site LS $\mathrm{Fe}^{3+}$ is narrower and the dominant peaks are located at higher energies by $\sim 11.7 \mathrm{meV}$ (Fig. 2b). Accordingly, NRIXS observations demonstrate a shift of the major peak to higher energy, from $\sim 25$ $\mathrm{meV}$ at $30 \mathrm{GPa}$ to $\sim 30 \mathrm{meV}$ at $100 \mathrm{GPa}$, and an increase in intensity at $\sim 45 \mathrm{meV}$ due to this B-site $\mathrm{LS} \mathrm{Fe}{ }^{3+}$ component. In order to match experimentally derived PDOS, the 272 best weights of the calculated PDOS of A-site HS Fe ${ }^{3+}$ and B-site LS $\mathrm{Fe}^{3+}$ are 70:30 273 (Fig. 2b). This difference in weight ratio implies that the inelastic component of B-site $274 \mathrm{LS} \mathrm{Fe}^{3+}$ from NRIXS measurements is significantly reduced across the spin transition. 275 This is also consistent with the pressure dependence of the Lamb-Mössbauer factor $(f)$ derived from NRIXS spectra (Fig. S2), which is directly controlled by the inelastic component ( $\left.S_{\text {inelastic }}\right)$ in the NRIXS spectra (Dauphas et al., 2018):

$$
f_{\mathrm{LM}}=1-\int_{E_{\min }}^{E_{\max }} S_{\text {inelastic }}(E) d E
$$

Across the spin transition of $\mathrm{B}$-site $\mathrm{Fe}^{3+}$ in $\left(\mathrm{Mg}_{0.5} \mathrm{Fe}^{3+}{ }_{0.5}\right)\left(\mathrm{Si}_{0.5} \mathrm{Fe}^{3+}{ }_{0.5}\right) \mathrm{O}_{3} \mathrm{Bdg}$, the linear slope of $f_{\mathrm{LM}}$ with respect to pressure increases from $6.7 \mathrm{e}^{-4} \mathrm{GPa}^{-1}$ at $25-60 \mathrm{GPa}$ to $1.6 \mathrm{e}^{-3}$ $\mathrm{GPa}^{-1}$ at $\sim 60-70 \mathrm{GPa}$ and changes to $3.7 \mathrm{e}^{-4} \mathrm{GPa}^{-1}$ above $\sim 70 \mathrm{GPa}$. Accounting for the 282 change in the inelastic scattering profile of $\mathrm{LS} \mathrm{Fe}^{3+}$, NRIXS experiments and DFT $+U$ calculation agree with complementary X-ray diffraction and X-ray emission spectroscopy observations about the conditions of the spin transition in Bdg. 


\subsection{Force constant of $\mathrm{Fe}$ and $\beta$-factors of ${ }^{56} \mathrm{Fe} /{ }^{54} \mathrm{Fe}$ for bridgmanite}

From experimental and theoretical PDOS, the force constant of iron $\langle F\rangle$ and the $\beta$-factors of ${ }^{56} \mathrm{Fe} /{ }^{54} \mathrm{Fe}$ for $\left(\mathrm{Mg}_{0.5} \mathrm{Fe}^{3+}{ }_{0.5}\right)\left(\mathrm{Si}_{0.5} \mathrm{Fe}^{3+}{ }_{0.5}\right) \mathrm{O}_{3}$ Bdg can be obtained within the harmonic approximation by following Eq. (6) and Eq. (7) (Dauphas et al., 2012):

$$
\begin{gathered}
<F>=\frac{M}{\hbar^{2}} \int_{0}^{+\infty} E^{2} g(E) d E \\
10^{3} \ln \beta=1000\left(\frac{1}{M^{54} \mathrm{Fe}}-\frac{1}{M^{56} \mathrm{Fe}}\right) \frac{\hbar^{2}}{8 k^{2} T^{2}}\langle F>
\end{gathered}
$$

Here $g(E)$ is PDOS, $M$ is the mass of a ${ }^{54} \mathrm{Fe}$ or ${ }^{56} \mathrm{Fe}$ nucleus, $k$ is Boltzmann's constant and $T$ is temperature in Kelvin. We find that $\langle F>$ obtained from calculated PDOS are significantly larger than those calculated from experimental PDOS (Fig. 3), especially at pressures $>60 \mathrm{GPa}$, although the calculated PDOS match well with experimental PDOS (Fig. 2 and S1). To find out the factors that result in the $\langle F\rangle$ differences, we calculated the evolution of $\langle F\rangle$ by changing the upper limit of energy $(x)$ for the integration by following Eq. (8):

$$
<F>=\frac{M}{\hbar^{2}} \int_{0}^{x} E^{2} g(E) d E \text {, (x increases from } 0 \text { to }+\infty \text { ) }
$$

As shown in Fig. 4, the integral values of $<F>$ from calculated PDOS agree well with those from experimental PDOS until energy for the integration reaches a threshold, above which the predicted $\langle F\rangle$ still increases with $x$ but the experimental one maintains a constant value (Fig. 4). This is mainly because the experimental PDOS intensity becomes indistinguishably close to zero due to the low signal noise ratio when energy is larger than $85 \mathrm{meV}$ at $32.5 \mathrm{GPa}$ and $110 \mathrm{meV}$ at $101.4 \mathrm{GPa}$, while the predicted PDOS from DFT $+U$ still have small non-zero values at these high-energy parts (Fig. 2). Amplified by the integral $E^{2} g(E)$, the small discrepancies in PDOS lead to significant differences in the final $\langle F>$ by $\sim 60 \mathrm{~N} / \mathrm{m}$ at $\sim 30 \mathrm{GPa}$ and $\sim 154 \mathrm{~N} / \mathrm{m}$ at $100 \mathrm{GPa}$. Similarly, the predicted PDOS of A-site $\mathrm{Fe}^{3+}$ and $\mathrm{Fe}^{2+}$ in Bdg also agree well with experimental measurements (Yang et al., 2019), but the $\langle F>$ from DFT $+U$ are larger than experimental values, especially at high pressures (Fig. S3 and S4). In contrast, both of the calculated PDOS and $\langle F\rangle$ of LS Fe in Fp agree well with experimental results (Fig. S5). As a consequence, we use theoretical results of Bdg in this study and experimental data of HS and LS Fp from Yang et al. (2019) for further modelling and discussion. 
317 within GGA/GGA $+\mathrm{U}$ underestimate the $<\mathrm{F}>$ of iron in goethite. However, in their DFT

318 calculations, the cell parameters of goethite were fixed to their experimental values and only atomic positions were relaxed. Because the GGA usually overestimates the volume, this incorrect strategy would put artificial stress on the structure and the true pressure 321 from the GGA calculations should be higher than ambient pressure (Wang et al., 2017a; 322 Wang et al., 2019b). This indicates that the iron $<\mathrm{F}>$ in Blanchard et al. (2015) was overestimated by their GGA/GGA+U calculations, and thus the $<\mathrm{F}>$ difference between NRIXS and DFT was underestimated. The discrepancy between NRIXS and GGA/GGA+U is mainly because the GGA underestimates the vibrational frequencies (Schauble, 2011), shifting the PDOS to lower values.

The changes of PDOS by different cation sites and spin states of $\mathrm{Fe}^{3+}$ result in variations in the corresponding $\langle F>$ and $\beta$-factors. For instance, as the PDOS of B-site $\mathrm{HS} \mathrm{Fe}^{3+}$ concentrates at higher energy range compared with the corresponding A-site $\mathrm{HS} \mathrm{Fe}^{3+}$ (Fig. 2 and $\mathrm{S} 1$ ), $<F>$ and $\beta$-factors are thus higher for $\mathrm{HS} \mathrm{Fe}^{3+}$ in the $\mathrm{B}$-site 331 than that in the A-site (Fig. 3 and Fig. 5). Notably, across the spin transition of the B332 site $\mathrm{Fe}^{3+}$ in $\left(\mathrm{Mg}_{0.5} \mathrm{Fe}^{3+}{ }_{0.5}\right)\left(\mathrm{Si}_{0.5} \mathrm{Fe}^{3+}{ }_{0.5}\right) \mathrm{O}_{3} \mathrm{Bdg}$ at $\sim 60 \mathrm{GPa}$, the $<F>$ and $\beta$-factors of $\mathrm{B}$ 333 site $\mathrm{Fe}^{3+}$ increases by $\sim 65 \%$.
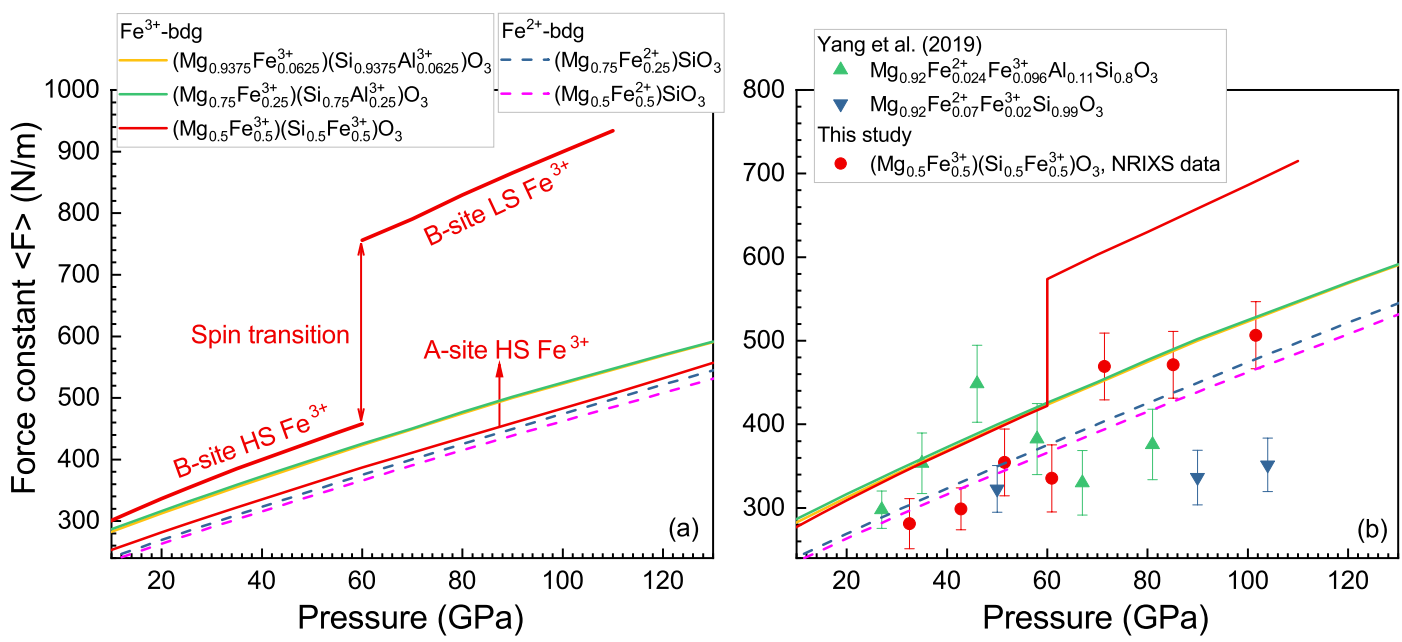

Figure 3. Force constant $<F>$ of iron in Bdg from DFT $+U$ calculations. (a) $<F>$ of A-site $\mathrm{Fe}^{2+}$, A-site $\mathrm{Fe}^{3+}$, and $\mathrm{B}$-site $\mathrm{Fe}^{3+}$ in $\mathrm{Bdg}$. Compared with the $<F>$ of A-site $\mathrm{Fe}^{2+}$, those of both Asite and $\mathrm{B}$-site $\mathrm{Fe}^{3+}$ in $\mathrm{Bdg}$ are higher at the same pressure. Across the spin transition of the $\mathrm{B}$ site $\mathrm{Fe}^{3+}$ in $\left(\mathrm{Mg}_{0.5} \mathrm{Fe}^{3+}{ }_{0.5}\right)\left(\mathrm{Si}_{0.5} \mathrm{Fe}^{3+}{ }_{0.5}\right) \mathrm{O}_{3} \mathrm{Bdg}$ at $\sim 60 \mathrm{GPa}$, the $<F>$ of $\mathrm{B}$-site $\mathrm{Fe}^{3+}$ increases by 
$\sim 65 \%$. (b) comparisons of in $<F>$ Bdg between theoretical and experimental results (Yang et

340 al., 2019). Although PDOS of $\mathrm{Fe}$ in $\mathrm{Bdg}$ from $\mathrm{DFT}+U$ agree well with experimental 341 measurements (Fig. 2, Fig. S1, and Fig. S3-S4), the predicted $\langle F>$ are significantly larger than 342 those from experimental PDOS, especially at high pressures.

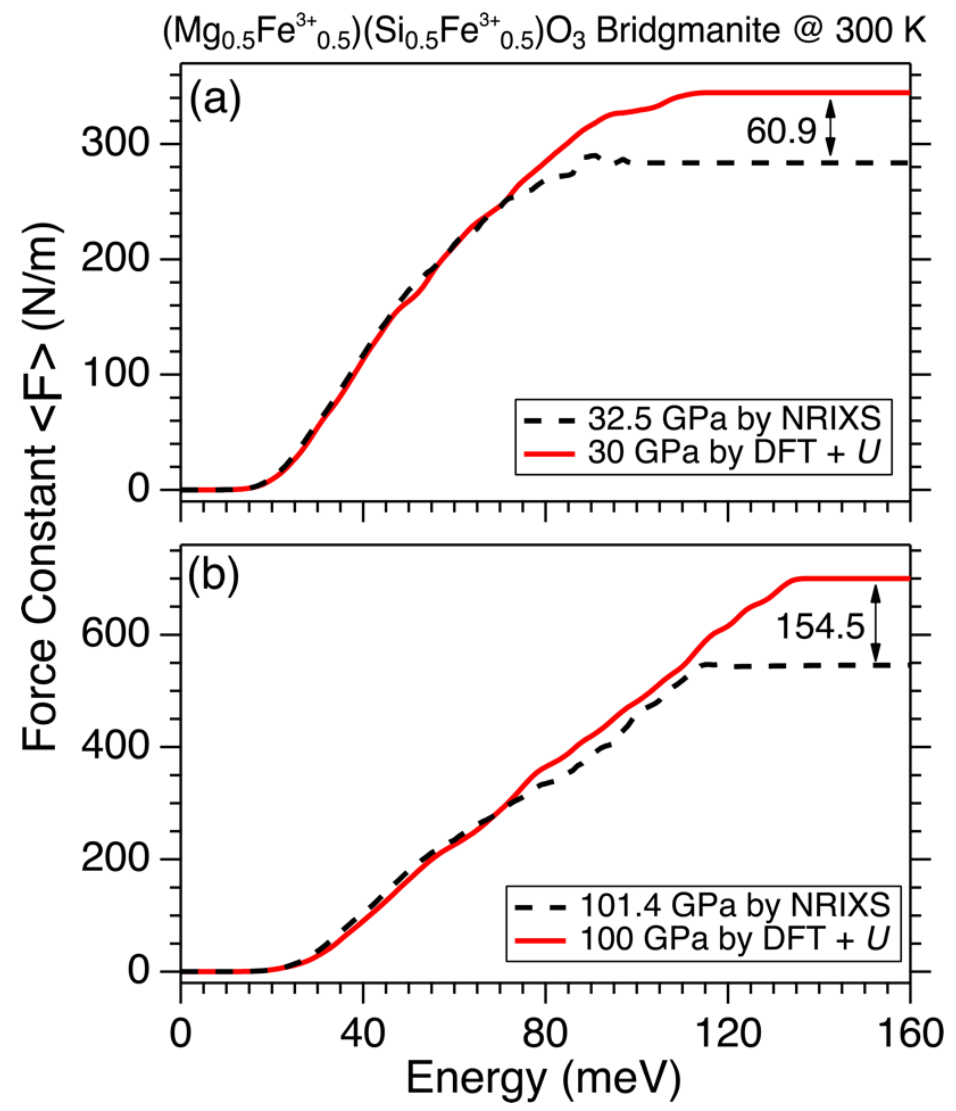

344 Figure 4. Evolution of $<F>$ of $\mathrm{Fe}^{3+}$ in $\left(\mathrm{Mg}_{0.5} \mathrm{Fe}^{3+}{ }_{0.5}\right)\left(\mathrm{Si}_{0.5} \mathrm{Fe}^{3+}{ }_{0.5}\right) \mathrm{O}_{3}$ Bdg with the upper limit of energy $(x)$ for the integration $\langle F\rangle=\frac{M}{\hbar^{2}} \int_{0}^{x} E^{2} g(E) d E$. The integral values of $\langle F\rangle$ from DFT $+U$ calculations agree well with experimental results when $x$ reaches a threshold, above which the predicted $\langle F>$ still increases with $x$ but the experimental one maintains a constant 348 value.

On the other hand, the $\beta$-factors can be also calculated from Eq. (1) within the 351 quasi-harmonic approximation (Urey equation). Following Bigeleisen and Mayer 352 (1947) and Kowalski et al. (2013), when the $\beta$-factor is expressed by the Taylor 353 expansions and the higher order terms are not taken into account, the Urey equation can 354 be then approximated by Eq. (7). The validity criteria restricts the usage of Eq. (6) to 355 frequencies $v\left[\mathrm{~cm}^{-1}\right] \leq 1.39 \mathrm{~T}[\mathrm{~K}]$ (Bigeleisen and Mayer, 1947; Kowalski et al., 
2013). Here we calculated the $\beta$-factors of Bdg with different chemical compositions

357 from their full phonon vibrational spectra using Eq. (1). Our calculated results show 358 that the $10^{3} \ln \beta$ of Bdg decreases in the order of LS- $\left(\mathrm{Mg}_{0.5} \mathrm{Fe}^{3+}{ }_{0.5}\right)\left(\mathrm{Si}_{0.5} \mathrm{Fe}^{3+}{ }_{0.5}\right) \mathrm{O}_{3}>\mathrm{HS}-$ $359\left(\mathrm{Mg}_{0.5} \mathrm{Fe}^{3+}{ }_{0.5}\right)\left(\mathrm{Si}_{0.5} \mathrm{Fe}^{3+}{ }_{0.5}\right) \mathrm{O}_{3} \quad>\quad\left(\mathrm{Mg}_{0.9375} \mathrm{Fe}^{3+}{ }_{0.0625}\right)\left(\mathrm{Si}_{0.9375} \mathrm{Al}^{3+}{ }_{0.0625}\right) \mathrm{O}_{3} \approx$ $360\left(\mathrm{Mg}_{0.75} \mathrm{Fe}^{3+}{ }_{0.25}\right)\left(\mathrm{Si}_{0.75} \mathrm{Al}_{0.25}\right) \mathrm{O}_{3}>\left(\mathrm{Mg}_{0.75} \mathrm{Fe}^{2+}{ }_{0.25}\right) \mathrm{SiO}_{3} \approx\left(\mathrm{Mg}_{0.5} \mathrm{Fe}^{2+}{ }_{0.5}\right) \mathrm{SiO}_{3}$ within 361 calculated pressure range. At $60 \mathrm{GPa}$ and $1000 \mathrm{~K}$, it varies from $1.58 \%$ for LS$362\left(\mathrm{Mg}_{0.5} \mathrm{Fe}^{3+}{ }_{0.5}\right)\left(\mathrm{Si}_{0.5} \mathrm{Fe}^{3+}{ }_{0.5}\right) \mathrm{O}_{3}$ to $0.98 \%$ for $\left(\mathrm{Mg}_{0.5} \mathrm{Fe}^{2+}{ }_{0.5}\right) \mathrm{SiO}_{3} \mathrm{Bdg}$ (Fig. 5a). Rustad and 363 Yin (2009) also calculated the $\beta$ factor of $\mathrm{Fe}^{2+}$-bearing Bdg using molecular clusters 364 and the $10^{3} \ln \beta$ of ${ }^{56} \mathrm{Fe} /{ }^{54} \mathrm{Fe}$ is $\sim 1.44 \%$ at $120 \mathrm{GPa}$ and $1000 \mathrm{~K}$, similar to our predictions 365 (1.42\%). However, it should be noted that the modelling of crystals using molecular 366 clusters breaks the intrinsic periodic boundary of crystals.
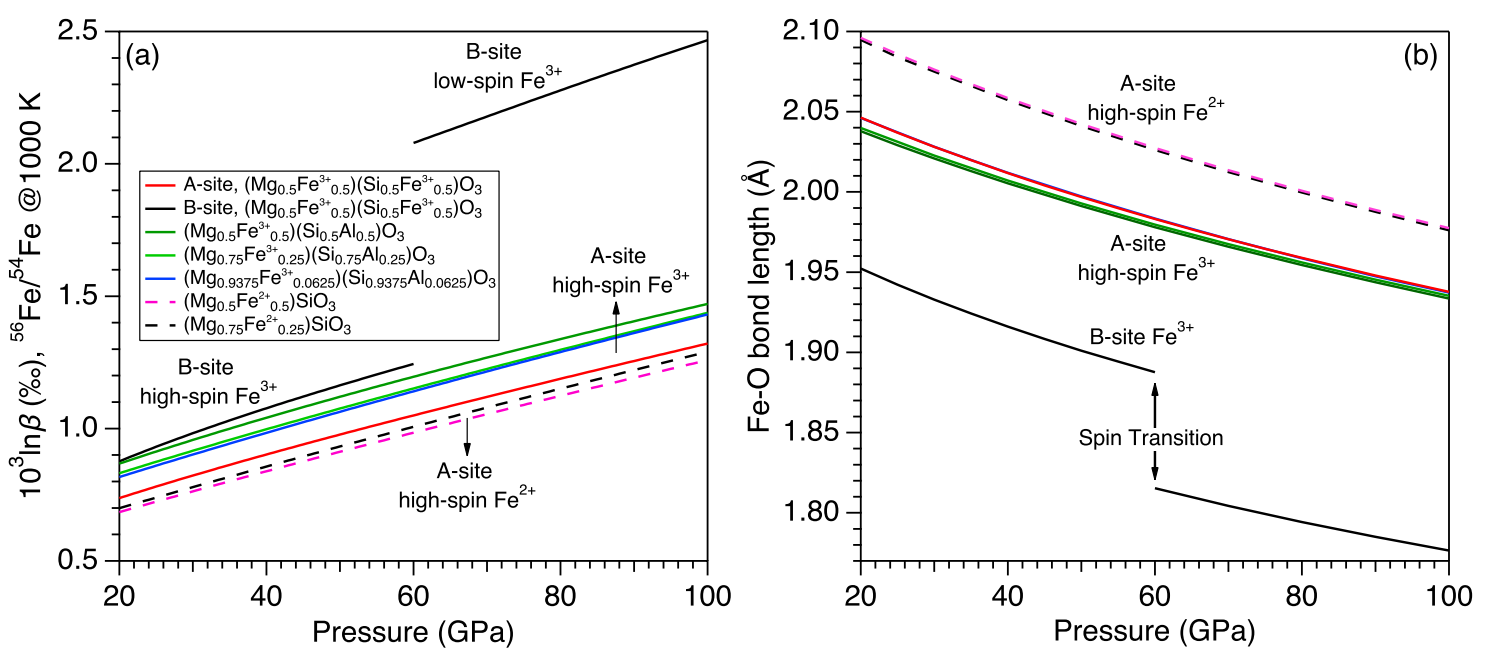

369 Figure 5. Comparisons between the ${ }^{56} \mathrm{Fe} /{ }^{54} \mathrm{Fe} \beta$-factors and the $\mathrm{Fe}-\mathrm{O}$ bond length of bdg at 30-

$370100 \mathrm{GPa}$ and $1000 \mathrm{~K}$ for different compositions in DFT $+U$ calculations. (a) Compared with the

$371 \beta$-factors of $\mathrm{Fe}^{2+}$ in the $\mathrm{A}$-site of $\mathrm{Bdg}$, those of both $\mathrm{A}$-site and $\mathrm{B}$-site $\mathrm{Fe}^{3+}$ in $\mathrm{Bdg}$ are higher at 372 the same $P-T$ condition. Across the spin transition of the B-site $\mathrm{Fe}^{3+}$ in $373\left(\mathrm{Mg}_{0.5} \mathrm{Fe}^{3+}{ }_{0.5}\right)\left(\mathrm{Si}_{0.5} \mathrm{Fe}^{3+}{ }_{0.5}\right) \mathrm{O}_{3} \mathrm{Bdg}$ at $\sim 60 \mathrm{GPa}$, the ${ }^{56} \mathrm{Fe}^{5 / 4} \mathrm{Fe} \beta$-factor of B-site $\mathrm{Fe}^{3+}$ at $1000 \mathrm{~K}$ 374 increases by $0.835 \%$. (b) The average Fe-O bond lengths in Bdg with different compositions 375 at static conditions. Across the spin transition of $\mathrm{B}$-site $\mathrm{Fe}^{3+}$ in $\left(\mathrm{Mg}_{0.5} \mathrm{Fe}^{3+}{ }_{0.5}\right)\left(\mathrm{Si}_{0.5} \mathrm{Fe}^{3+}{ }_{0.5}\right) \mathrm{O}_{3} \mathrm{Bdg}$ 376 at $\sim 60 \mathrm{GPa}$, the lengths of $\mathrm{A}$-site and $\mathrm{B}$-site $\mathrm{Fe}^{3+}$ decrease by $0.014 \AA$ and $0.0 .072 \AA$, 377 respectively. In contrast, the concentration effect on both $\mathrm{A}$-site $\mathrm{Fe}^{2+}-\mathrm{O}$ and $\mathrm{A}$-site $\mathrm{Fe}^{3+}-\mathrm{O}$ bond 378 lengths in Bdg is negligible. 


\section{Discussion}

381 4.1 Effects of site occupancy, spin transition, chemical composition, and valence state on $\beta$-factors of Bdg

The pressure dependences of $\beta$-factors of Bdg are controlled by multiple factors as shown in Fig. 2a. Here we show the $\beta$-factors anchored at $1000 \mathrm{~K}$ as a representative temperature to address these effects since the factors are almost linearly proportional to $1 / T^{2}$ at different pressures (Fig. S6). In $\left(\mathrm{Mg}_{0.5} \mathrm{Fe}^{3+}{ }_{0.5}\right)\left(\mathrm{Si}_{0.5} \mathrm{Fe}^{3+}{ }_{0.5}\right) \mathrm{O}_{3} \mathrm{Bdg}$, compared to the A-site $\mathrm{HS} \mathrm{Fe}^{3+}$, B-site $\mathrm{HS} \mathrm{Fe}^{3+}$ has a higher $\beta$-factor and the difference between two sites is $\sim 0.17 \%$ at $40 \mathrm{GPa}$ and $1000 \mathrm{~K}$ (Fig. 5a). This is also consistent with the much shorter bond lengths, and correspondingly higher bond strength, of $\mathrm{Fe}^{3+}-\mathrm{O}$ in the 6coordinated B-site relative to the 8-coordinated A-site (Fig. 5b). B-site $\mathrm{Fe}^{3+}$ in Bdg is expected to undergo a HS to LS transition at middle-mantle depths (Catalli et al., 2010; Hsu et al., 2011; Mao et al., 2015; Shukla and Wentzcovitch, 2016; Fu et al., 2018b; Liu et al., 2018). The spin transition of the $\mathrm{B}$-site $\mathrm{Fe}^{3+}$ in $\left(\mathrm{Mg}_{0.5} \mathrm{Fe}^{3+}{ }_{0.5}\right)\left(\mathrm{Si}_{0.5} \mathrm{Fe}^{3+}{ }_{0.5}\right) \mathrm{O}_{3}$ Bdg occurs at $~ 50 \mathrm{GPa}$ (Liu et al., 2018), which leads to shortening of the average Bsite $\mathrm{Fe}^{3+}-\mathrm{O}$ bonds by $0.072 \AA$, equal to $3.8 \%$ relative change (Fig. 5 b). Such a change in the average $\mathrm{Fe}-\mathrm{O}$ bond induces an increase of $0.83 \%$ in the $\beta$-factor of $\mathrm{B}$-site $\mathrm{Fe}^{3+}$ at $1000 \mathrm{~K}$ and $0.21 \%$ at $2000 \mathrm{~K}$ (Fig. S6). However, the spin transition of the B-site $\mathrm{Fe}^{3+}$ does not significantly change the $\mathrm{A}$-site $\mathrm{Fe}^{3+}-\mathrm{O}$ bonds and the $\beta$-factor of $\mathrm{A}$-site $\mathrm{Fe}^{3+}$.

399 Thus, the contrast between the $\beta$-factors of B-site and A-site $\mathrm{Fe}^{3+}$ is also strongly 400 enhanced by the Fe spin transition in the B-site from $0.19 \%$ to $1.01 \%$ at $1000 \mathrm{~K}$ and $40160 \mathrm{GPa}$ (Fig. 5a).

402 The presence of $\mathrm{Al}$ in $\mathrm{Bdg}$ will weaken the effect of $\mathrm{B}$-site $\mathrm{Fe}^{3+}$ spin transition on 403 its $\beta$-factor by preventing $\mathrm{Fe}^{3+}$ from occupying the $\mathrm{B}$-site. Depending on the bulk $404 \mathrm{Al} / \mathrm{Fe}^{3+}$ molar ratio, $\mathrm{Al}^{3+}$ can either occupy the $\mathrm{B}$-site only with $\mathrm{Fe}^{3+}$ filling in the $\mathrm{A}$ 405 site or it occupies both the B-site and the available A-site left by A-site $\mathrm{Fe}^{3+}$ (Lin et al., 406 2013; Liu et al., 2015). For Al/ $\mathrm{Fe}^{3+}$ molar ratio equal to 1 , all $\mathrm{Fe}^{3+}$ would occupy the A407 site and all $\mathrm{Al}$ stays in the $\mathrm{B}$-site. Here we calculated the $\beta$-factors of three $\mathrm{Fe}^{3+}$ - and 408 Al-bearing Bdg with different $\mathrm{FeAlO}_{3}$ concentration at $1000 \mathrm{~K}$ to illustrate the 409 compositional dependence of both $\mathrm{Fe}^{3+}-\mathrm{O}$ bond length and the $\beta$-factor of ${ }^{56} \mathrm{Fe} /{ }^{54} \mathrm{Fe}$ (Fig. 
410 5a). Our results show that the incorporation of $6.25-50 \mathrm{~mol} \% \mathrm{FeAlO}_{3}$ into $\mathrm{Bdg}$ only 411 changes the A-site $\mathrm{Fe}^{3+}-\mathrm{O}$ bond length by 0-0.007 $\AA$ under lower-mantle pressures (Fig. $4125 \mathrm{~b}$ ). As the Fe-O bond length controls the magnitude of the corresponding $\beta$-factor (Fig. $413 \mathrm{~S} 7)$, the effect of $\mathrm{FeAlO}_{3}$ concentration on the $\beta$-factors of the A-site $\mathrm{Fe}^{3+}$ is 414 insignificant. For example, the largest difference in the $\beta$-factor of $\mathrm{Al}^{3+}$ - and $\mathrm{Fe}^{3+}-$ 415 bearing $\mathrm{Bdg}\left(\mathrm{Mg}_{0.9375} \mathrm{Fe}^{3+}{ }_{0.0625}\right)\left(\mathrm{Si}_{0.9375} \mathrm{Al}^{3+}{ }_{0.0625}\right) \mathrm{O}_{3},\left(\mathrm{Mg}_{0.75} \mathrm{Fe}^{3+}{ }_{0.25}\right)\left(\mathrm{Si}_{0.75} \mathrm{Al}_{0.25}\right) \mathrm{O}_{3}$, 416 and $\left(\mathrm{Mg}_{0.5} \mathrm{Fe}^{3+}{ }_{0.5}\right)\left(\mathrm{Si}_{0.5} \mathrm{Al}^{3+}{ }_{0.5}\right) \mathrm{O}_{3}$ is smaller than $0.06 \%$ at $1000 \mathrm{~K}$ and all pressures (Fig. 417 5a). In contrast, the $\beta$-factor of $\mathrm{A}$-site $\mathrm{Fe}^{3+}$ in $\left(\mathrm{Mg}_{0.5} \mathrm{Fe}^{3+}{ }_{0.5}\right)\left(\mathrm{Si}_{0.5} \mathrm{Al}^{3+}{ }_{0.5}\right) \mathrm{O}_{3} \mathrm{Bdg}$ is $\sim 0.14 \%$ 418 larger than that of $\mathrm{A}$-site $\mathrm{Fe}^{3+}$ in $\left(\mathrm{Mg}_{0.5} \mathrm{Fe}^{3+}{ }_{0.5}\right)\left(\mathrm{Si}_{0.5} \mathrm{Fe}^{3+}{ }_{0.5}\right) \mathrm{O}_{3} \mathrm{Bdg}$, consistent with 419 relatively shorter $\mathrm{Fe}^{3+}-\mathrm{O}$ bonds in the $\mathrm{A}$ site of $\left(\mathrm{Mg}_{0.5} \mathrm{Fe}^{3+}{ }_{0.5}\right)\left(\mathrm{Si}_{0.5} \mathrm{Al}^{3+}{ }_{0.5}\right) \mathrm{O}_{3} \mathrm{Bdg}(\mathrm{Fig}$. 420 5b). This reveals that the speciation of $\mathrm{B}$-site ion $\left(\mathrm{Fe}^{3+}\right.$ or $\left.\mathrm{Al}^{3+}\right)$ also has a mild effect 421 on the $\mathrm{A}$-site $\mathrm{Fe}^{3+}-\mathrm{O}$ bond strength and its $\beta$-factor. However, such an effect of $\mathrm{Al}$ on $422 \mathrm{~A}$-site $\mathrm{Fe}^{3+} \beta$-factor is much weaker than the influence of spin transition and can be 423 further diminished by mantle high temperatures, which results in only $0-0.01 \%$ o 424 difference in $\beta$-factor along the normal lower-mantle geotherm (Fig. 6). As long as some $\mathrm{Fe}^{3+}$ occupies the $\mathrm{Bdg} \mathrm{B}$-site, the change in $\beta$-factor due to the spin transition is 426 independent of the identity of other ions on A- and B-site. Therefore, although $\mathrm{Al}^{3+}$ 427 incorporation itself does not change the Bdg structure enough to impact isotopic 428 fractionation, it prevents $\mathrm{Fe}^{3+}$ from occupying the $\mathrm{B}$-site and thus reduces the significant 429 impact of $\mathrm{B}$-site $\mathrm{Fe}^{3+}$ spin transition on the $\beta$-factor of $\mathrm{Bdg}$.

430 In addition to $\mathrm{Fe}^{3+}$, the $\mathrm{A}$ site in $\mathrm{Bdg}$ is also large enough to accommodate $\mathrm{Fe}^{2+}$, 431 which maintains a HS state in Bdg throughout the lower mantle. The $\mathrm{Fe}^{2+}$-bearing Bdg 432 compositions in our DFT $+U$ calculations, $\left(\mathrm{Mg}_{0.5} \mathrm{Fe}^{2+}{ }_{0.5}\right) \mathrm{SiO}_{3}$ and $\left(\mathrm{Mg}_{0.75} \mathrm{Fe}^{2+}{ }_{0.25}\right) \mathrm{SiO}_{3}$, 433 have the smallest $\beta$-factors that are also insensitive to the $\mathrm{Fe}^{2+}$ content (Fig. 5a). This 434 difference in $\beta$-factor between $\mathrm{A}$-site $\mathrm{Fe}^{3+}$ and $\mathrm{Fe}^{2+}$ ranges from $0.04 \%$ to $0.15 \%$ at $4351000 \mathrm{~K}$ (Fig. 5a) but will be diminished along an expected geotherm of the lower mantle 436 (Fig. 6). In particular, the $\beta$-factor increases with pressure along the adiabat, because 437 the increase due to compression outweighs the decrease from the $1 / \mathrm{T}^{2}$ dependence. The 438 enrichment of light $\mathrm{Fe}$ isotopes in $\mathrm{Fe}^{2+}$-bearing $\mathrm{Bdg}$ relative to other $\mathrm{Fe}^{3+}$-bearing 439 species is mainly caused by the longer $\mathrm{Fe}^{2+}-\mathrm{O}$ bond lengths than those $\mathrm{Fe}^{3+}-\mathrm{O}$ bonds 440 (Fig. 5b and S7). Moreover, the valence state also partially contributes to the smaller $\beta$ - 
441 factors of $\mathrm{Fe}^{2+}$-bearing $\mathrm{Bdg}$ as revealed by the longer $\mathrm{Fe}-\mathrm{O}$ bond length of HS A-site $442 \mathrm{Fe}^{2+}$ than that of HS A-site $\mathrm{Fe}^{3+}$ (Fig. S7). In summary, the pressure- and temperature 443 dependent $\beta$-factor of ${ }^{56} \mathrm{Fe} /{ }^{54} \mathrm{Fe}$ for $\mathrm{Bdg}$ is controlled by the $\mathrm{Fe}^{3+} / \mathrm{Fe}^{2+}, \mathrm{Al} / \mathrm{Fe}^{3+}$, and spin 444 transition if there is some $\mathrm{Fe}^{3+}$ accommodated in $\mathrm{B}$ site.

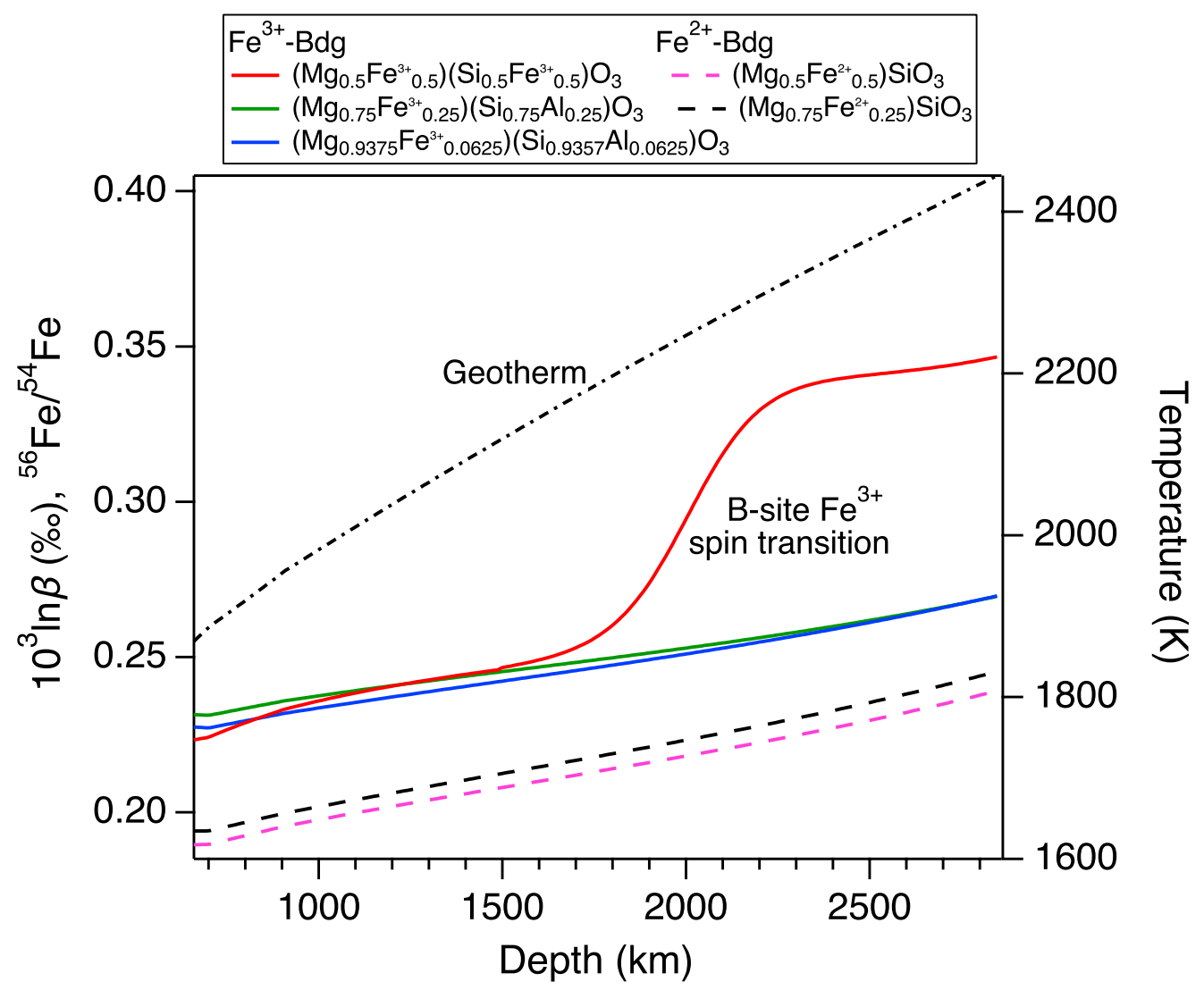

Figure 6. ${ }^{56} \mathrm{Fe} /{ }^{54} \mathrm{Fe} \beta$-factors of various Bdg compositions computed by $\mathrm{DFT}+U$ along an 448 adiabat representative of the average lower mantle. As the B-site $\mathrm{Fe}^{3+}$ undergoes high-spin to 449 low-spin transition, the ${ }^{56} \mathrm{Fe} /{ }^{54} \mathrm{Fe} \beta$-factor of $\left(\mathrm{Mg}_{0.5} \mathrm{Fe}^{3+}{ }_{0.5}\right)\left(\mathrm{Si}_{0.5} \mathrm{Fe}^{3+}{ }_{0.5}\right) \mathrm{O}_{3}$ Bdg increases by $450 \sim 0.09 \%$ across the spin transition of the B-site $\mathrm{Fe}^{3+}$. The expected geotherm (dot dash line) was 451 taken from Brown and McQueen (1986).

\subsection{Fe isotopic fractionation in the deep mantle}

\subsubsection{Inter-mineral iron isotope fractionation}

The ${ }^{56} \mathrm{Fe} /{ }^{54} \mathrm{Fe} \beta$-factor of Bdg and $\mathrm{Fp}$ as a function of depth in likely bulk mantle compositions can be used to estimate fractionation of Fe isotopes in the deep Earth. The depth-dependence of Fe isotopic fractionation between Bdg and Fp in the lower mantle 
is modelled based on the following equations:

$$
\begin{gathered}
\Delta^{56} \mathrm{Fe}_{\mathrm{Bdg}-\mathrm{Fp}}=\delta^{56} \mathrm{Fe}_{\mathrm{Bdg}}-\delta^{56} \mathrm{Fe}_{\mathrm{Fp}} \\
\delta^{56} \mathrm{Fe}_{\mathrm{LM}}=\mathrm{n}_{\mathrm{Bdg}} \times \delta^{56} \mathrm{Fe}_{\mathrm{Bdg}}+\mathrm{n}_{\mathrm{Fp}} \times \delta^{56} \mathrm{Fe}_{\mathrm{Fp}}
\end{gathered}
$$

where $\delta^{56} \mathrm{Fe}_{\mathrm{Bdg}}, \delta^{56} \mathrm{Fe}_{\mathrm{Fp}}$, and $\delta^{56} \mathrm{Fe}_{\mathrm{LM}}$ are the $\mathrm{Fe}$ isotopic compositions of $\mathrm{Bdg}, \mathrm{Fp}$, and the bulk lower mantle, respectively. $\delta^{56} \mathrm{Fe}_{\mathrm{LM}}$ is set to 0 as the representative chondritic value (Craddock and Dauphas, 2011). $\mathrm{n}_{\mathrm{Bdg}}$ and $\mathrm{n}_{\mathrm{Fp}}$ are the Fe fractions in Bdg and Fp (Table S1), respectively, based on a pyrolitic lower mantle composition (Irifune et al., 2010). The pressure effect, including the pressure-induced spin transition, is taken into account on the evaluation of $\beta$-factors of Bdg and Fp.

Previous studies (Wang et al., 2015; Zhang et al., 2016; Wu, 2016) suggested that the lower mantle may be represented by a pyrolitic composition with $\sim 8 \mathrm{wt} \% \mathrm{FeO}$ and a Al/Fe ratio $\sim 0.8$ (McDonough and Sun, 1995). The lower-mantle $\mathrm{Fe}^{3+} / \Sigma \mathrm{Fe}$ ratio range was thought to be higher than 0.5 (Frost and McCammon, 2008), and the $\mathrm{Fe}^{3+} / \Sigma \mathrm{Fe}$ ratio of Bdg could be 0.5-1 for most part of the lower mantle (Wang et al., 2015). Because the site occupancy of $\mathrm{Fe}^{3+}$ is controlled by $\mathrm{Al}^{3+} / \mathrm{Fe}^{3+}$ ratios (Frost et al., 2004; Lin et al., 2013; Liu et al., 2015; Liu et al., 2018), we consider three different endmembers for Bdg compositions: (1) $\mathrm{Fe}^{3+}$ - and $\mathrm{Al}^{3+}$-free, $\mathrm{Fe}^{2+}$-bearing; (2) $\mathrm{Fe}^{3+}$ - and $\mathrm{Al}^{3+}$-bearing (3) $\mathrm{Fe}^{3+}$-bearing but $\mathrm{Al}^{3+}$-free (Fig. 7). These three endmembers demonstrate the range of possible compositional effects on Fe isotopic compositions of Bdg and Fp in the lower mantle:

1) For a simplified $\mathrm{Fe}^{3+}$ - and $\mathrm{Al}^{3+}$-free, $\mathrm{Fe}^{2+}$-bearing system, the major factor that impacts $\mathrm{Fe}-\mathrm{O}$ bonds and $\mathrm{Fe}$ isotopic fractionation is the spin transition of $\mathrm{Fe}^{2+}$ in Fp at mid-lower-mantle depths. In this system, there is no significant iron fractionation between $\mathrm{Bdg}$ and $\mathrm{Fp}\left(\Delta^{56} \mathrm{Fe}_{\mathrm{Bdg}-\mathrm{Fp}}=0-0.02 \%\right)$ below $60 \mathrm{GPa}$. The spin transition occurs only in Fp at $\sim 60-120 \mathrm{GPa}$, and increases the $\beta$-factor of Fp. This effect significantly decreases $\Delta^{56} \mathrm{Fe}_{\mathrm{Bdg}-\mathrm{Fp}}$ from $0 \%$ at $\sim 60 \mathrm{GPa}$ to $-0.17 \%$ at $\sim 120 \mathrm{GPa}$ (Fig. 7a). As a result, Fp would be enriched in ${ }^{56} \mathrm{Fe}$ with $\delta^{56} \mathrm{Fe}$ up to $0-0.08 \%$ below mid-lower mantle and $\delta^{56} \mathrm{Fe}_{\mathrm{Bdg}}$ would be as low as $-0.07 \%$ (Fig. 7b).

2) For a more realistic $\mathrm{Fe}^{3+}$ - and $\mathrm{Al}^{3+}$-bearing system with the $\mathrm{Fe}^{3+} / \mathrm{Al}$ ratio of $<1$, our computational results suggest that the presence of $\mathrm{Fe}^{3+}$ in the Bdg A-site 
increases the $\beta$-factor of $\mathrm{Bdg}$ by $0.03-0.04 \%$ along an expected geotherm (Fig. 6). No significant difference across the spin transition of $\mathrm{B}$-site $\mathrm{Fe}^{3+}$ in $\mathrm{Bdg}$ is expected in this composition relative to the $\mathrm{Fe}^{3+}$ - and $\mathrm{Al}^{3+}$-free, but $\mathrm{Fe}^{2+}$-bearing system. Therefore, $\Delta^{56} \mathrm{Fe}_{\mathrm{Bdg} \text {-Fp }}$ of the $\mathrm{Fe}^{3+}$ - and $\mathrm{Al}^{3+}$-bearing system is $\sim 0.03$ composition. Therefore, the $\Delta^{56} \mathrm{Fe}_{\mathrm{Bdg} \text {-Fp }}$ in a pyrolitic or harzburgitic composition is

514 (such as banded iron formation and goethite) could be carried to the lower mantle by 515 subducted slabs, resulting in local chemical heterogeneous regions enriched in $\mathrm{Fe}^{3+}$. 516 Under such a scenario, Bdg may have much lower Al content and higher $\mathrm{Fe}^{3+}$ content, 517 and therefore more $\mathrm{Fe}^{3+}$ could occupy both the A-site and B-site by the coupled 518 substitution mechanism (Frost et al., 2004; Liu et al., 2015; Shim et al., 2017; Liu et al., 519 2018). Compared with $\mathrm{Fe}^{3+}$ - and $\mathrm{Al}^{3+}$-bearing Bdg forming in a pyrolitic composition, 
520 the spin transition of the B-site $\mathrm{Fe}^{3+}$ in Bdg would increase $\Delta^{56} \mathrm{Fe}_{\mathrm{Bdg} \text {-Fp }}$ by as much as $521 \quad 0.08 \%$ (Fig. 7b), which slightly exceeds the highest precision measurements of $\delta^{56} \mathrm{Fe}$ 522 ( 0.03\%o, Sossi et al., 2015). Overall, Fe isotopic fractionation between Bdg and Fp is 523 insignificant in most parts of the lower mantle, except the lowermost parts (Fig. 7). In 524 the upper and middle part of the lower mantle, the stronger $\mathrm{Fe}-\mathrm{O}$ bond strength in $\mathrm{Fe}^{3+}$ 525 enriched Bdg would only enrich Bdg in ${ }^{56} \mathrm{Fe}$ with $\delta^{56} \mathrm{Fe}_{\mathrm{Bdg}}$ as high as $+0.02 \%$, with 526 correspondingly indistinguishable $\Delta^{56} \mathrm{Fe}_{\mathrm{Bdg}-\mathrm{Fp}}$ in these depths based on the highest 527 precision of MC-ICP-MS measurements ( 0.03\%, Sossi et al., 2015). In the lowermost 528 lower mantle, the spin transition of $\mathrm{Fe}^{2+}$ in $\mathrm{Fp}$ would lead to the enrichment of heavy $529 \mathrm{Fe}$ in Fp with $\Delta^{56} \mathrm{Fe}_{\mathrm{Bdg}-\mathrm{Fp}}$ as low as $-0.15 \%$ in a pyrolitic composition. For the $\mathrm{Fe}^{3+}$-rich 530 but Al-poor system, the spin transition of B-site $\mathrm{Fe}^{3+}$ in Al-poor Bdg would diminish $531 \Delta^{56} \mathrm{Fe}_{\mathrm{Bdg}-\mathrm{Fp}}$, making the $\mathrm{Fe}$ isotopic compositions of the coexisting oxidized Bdg and $\mathrm{Fp}$ 532 indistinguishable (Fig. 7b). Therefore, the magnitude of $\Delta^{56} \mathrm{Fe}_{\mathrm{Bdg} \text {-Fp }}$ in a pyrolitic 533 composition would probably exceed the technical resolution for $\mathrm{Fe}$ isotope 534 measurements in the lowermost lower mantle, whereas no significant $\Delta^{56} \mathrm{Fe}_{\mathrm{Bdg} \text {-Fp }}$ would 535 be found in the $\mathrm{Fe}^{3+}$-rich but Al-poor system.
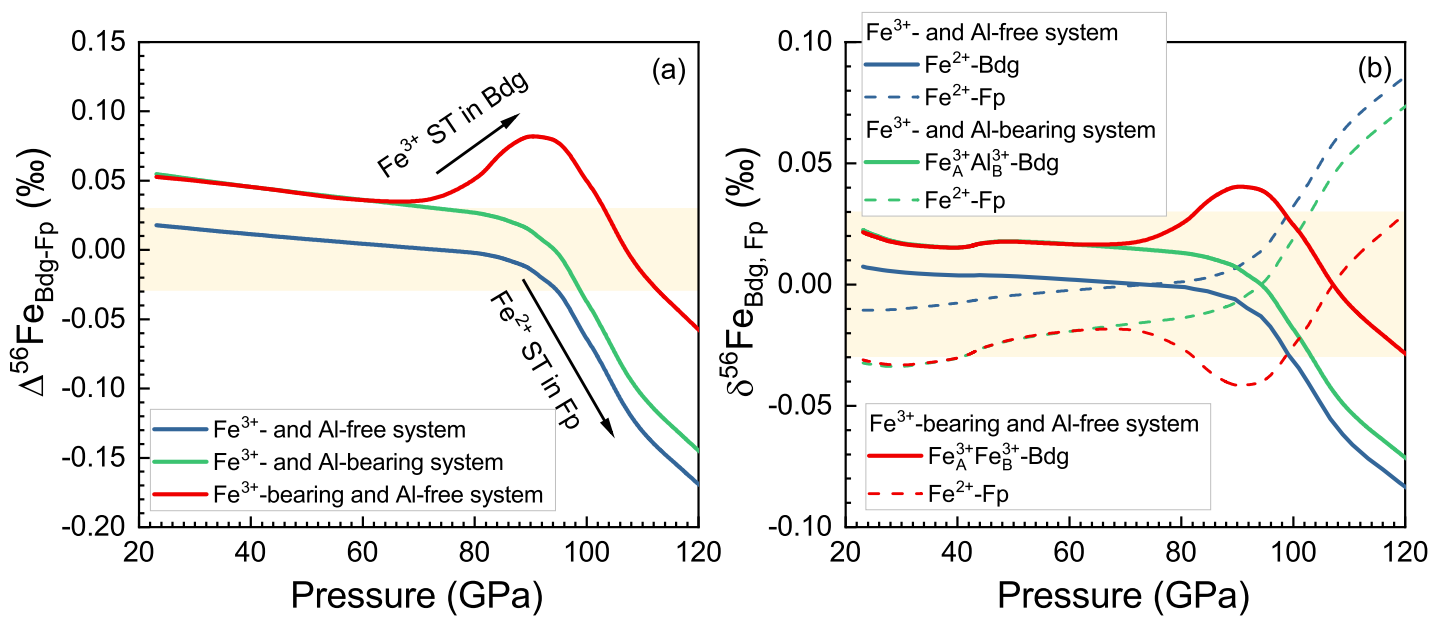

538 Figure 7. Equilibrium ${ }^{56} \mathrm{Fe} /{ }^{54} \mathrm{Fe}$ isotopic fractionation between coexisting Bdg and $\mathrm{Fp}$ (a) and

539 the corresponding Fe isotopic compositions of these two phases (b) along an expected geotherm

540 (Brown and McQueen, 1986). Solid and dash lines in (b) represent Fe isotopic compositions of

541 Bdg and Fp, respectively. Three compositional assemblages are considered: $\mathrm{Fe}^{3+}$-bearing but 542 Al-free system (red curves); $\mathrm{Fe}^{3+}$ - but Al-bearing system (green curves) and $\mathrm{Fe}^{3+}$ - and $\mathrm{Al}$-free 543 system (blue curves). The light yellow areas represent the best resolution of MC-ICP-MS 
544 measurements $\left(\sim 0.03 \%\right.$, Sossi et al., 2015). The spin transition (ST) of Fe ${ }^{2+}$ in Fp would occur 545 at the middle depth of the lower mantle, where only the B-site $\mathrm{Fe}^{3+}$ in Bdg would undergo a HS 546 to LS transition at $\sim 60 \mathrm{GPa}$.

\subsubsection{Iron isotope fractionation during magma ocean crystallization}

In addition to the possible $\mathrm{Fe}$ isotope fractionation between solid phases, how $\mathrm{Fe}$ isotopes would be fractionated between silicate melts and minerals during magma ocean crystallization (Boukaré et al., 2015) is also important for understanding the variability in iron isotopic composition in deep mantle (Yang et al., 2019). Based on the $<F>$ of solid phases and basaltic glass, Yang et al. (2019) investigated the evolution of

554 Fe isotopic fractionation during terrestrial magma ocean crystallization and found no 555 significant Fe fractionation between minerals and silicate melts. Here, following the model proposed in Yang et al. (2019), we also revaluated the Fe isotope fractionation

557 between $\mathrm{Bdg}+\mathrm{Fp}$ and silicate melts during magma ocean crystallization using the $<F>$

558 of Bdg from DFT $+U$ calculations in this study. The $<\mathrm{F}>$ of solid phase was calculated 559 from the $<\mathrm{F}>$ of Fp and Bdg using $<\mathrm{F}>_{\text {sum }}=\mathrm{n}_{\mathrm{Fp}} *<\mathrm{F}>_{\mathrm{Fp}}+\mathrm{n}_{\mathrm{Bdg}} *<\mathrm{F}>_{\mathrm{Bdg}}$, where $\mathrm{n}_{\mathrm{Fp}}$ and $\mathrm{n}_{\mathrm{Bdg}}$ 560 are the fractions of iron in Fp and Bdg in the solid phase, respectively, and $\mathrm{n}_{\mathrm{Fp}}+\mathrm{n}_{\mathrm{Bdg}}=1$.

561 The $<F>$ of basaltic glass extrapolated to $130 \mathrm{GPa}$ was used as an analogue to basaltic 562 melts (Liu et al., 2017). The chemical compositions of solid aggregates and the residual 563 melt were calculated after each $1 \mathrm{wt} \%$ increment of crystallization and can be found in 564 Yang et al. (2019). Fractional crystallization and a mass-balance relationship were used 565 in the model. For the $\mathrm{i}^{\text {th }}$ separation of solids, the isotopic composition of solids 566 equilibrated with the residual melt can be calculated by $\delta^{56} \mathrm{Fe}_{\text {solids-i+1 }}=\delta^{56} \mathrm{Fe}_{\text {melts- }}$ $567 \quad \mathrm{i}+\Delta^{56} \mathrm{Fe}_{\text {solids-melts. }}$ Based on the isotopic mass balance, we have:

$\delta^{56} \mathrm{Fe}_{\text {melts-i+1 }}=\left[\delta^{56} \mathrm{Fe}_{\text {melts-i- }}\left(\delta^{56} \mathrm{Fe}_{\text {melts-i }}+\Delta^{56} \mathrm{Fe}_{\text {solids-melts }}\right) * \mathrm{n}_{\text {solid }}\right] /\left(1-\mathrm{n}_{\text {solids }}\right)(11)$

$569 \quad \delta^{56} \mathrm{Fe}_{\text {solids-i+1 }}=-\delta^{56} \mathrm{Fe}_{\text {melts-i+1 } 1} * \mathrm{n}_{\text {melts }} /\left(1-\mathrm{n}_{\text {melts }}\right)(12)$

570 where $\mathrm{n}_{\text {solids }}$ is the fraction of iron taken up by solids at each step and $\mathrm{n}_{\text {melts }}$ is the fraction 571 of total iron in the remaining melt. We note that the chemical composition of residual 572 melt would be dominated by $\mathrm{FeO}(\mathrm{Fe} /(\mathrm{Fe}+\mathrm{Mg})>60 \%)$ when the fraction of melt is 573 lower than $10 \%$ with temperature decreasing to $4200 \mathrm{~K}$ (Figure 7 in Boukare et al., 574 2015). At this stage, the $<F>$ of basaltic glass may not be used as an analogue to silicate 
575 melts due to the large difference in chemical compositions, and we stopped the 576 simulations.

577 Our results show that silicate melts are isotopically lighter than Bdg+Fp but the $578 \Delta^{56} \mathrm{Fe}_{\text {solids-melts }}$ are smaller than $+0.03 \%$ for $\mathrm{Fe}^{2+}$-bearing and $\mathrm{Fe}^{3+}$-free systems and $579 \mathrm{Fe}^{3+}$ - and $\mathrm{Al}^{3+}$-bearing system. $\mathrm{As} \mathrm{Fe}^{3+}$ is generally not expected to occupy the Bdg B580 site in a pyrolitic lower mantle with the $\mathrm{Al} / \mathrm{Fe}^{3+}$ ratios of higher than 1 , it can be 581 concluded that no significant $\mathrm{Fe}$ isotope fractionation between $\mathrm{Bdg}+\mathrm{Fp}$ and silicate melt 582 has been produced during the crystallization process. For the $\mathrm{Fe}^{3+}$-bearing but Al-poor 583 system, $\Delta^{56} \mathrm{Fe}_{\text {solids-melts }}$ could be up $+0.06 \%$, if we also used the $\langle F>$ of basaltic melts 584 as an analogue to $\mathrm{Fe}^{3+}$-rich melts. However, $\mathrm{Fe}^{3+}$-rich melts should be expected to be 585 enriched in heavy Fe isotopes relative to the $\mathrm{Fe}^{2+}$-rich one (Dauphas et al., 2014), 586 because the $<\mathrm{F}>$ of $\mathrm{Fe}^{3+}$-bearing silicate glass is $\sim 150 \mathrm{~N} / \mathrm{m}$ larger than that of $\mathrm{Fe}^{2+}$ 587 bearing silicate glass (Dauphas et al., 2014). As a result, the $<F>$ of $\mathrm{Fe}^{3+}$-rich melts 588 were underestimated in this case and the $\Delta^{56} \mathrm{Fe}_{\text {solids-melts }}$ (up $+0.06 \%$ ) could have been 589 overestimated by $0.025 \%$, if the $<F>$ difference between $\mathrm{Fe}^{3+}$-rich and $\mathrm{Fe}^{2+}$-rich melts 590 at $130 \mathrm{GPa}$ is modeled by the value for silicate glasses at ambient pressure (Dauphas et 591 al., 2014). Although the $\left\langle F>\right.$ of $\mathrm{Fe}^{3+}$-rich melts at $130 \mathrm{GPa}$ are still unknown, the 592 crystallization process of $\mathrm{Fe}^{3+}$-rich melts in some local regions also cannot produce 593 resolvable Fe isotope fractionation between solids and melts. Therefore, we suggest 594 that crystallization of the magma ocean is unlikely to have resulted in significant iron 595 isotopic fractionation in deep mantle. 


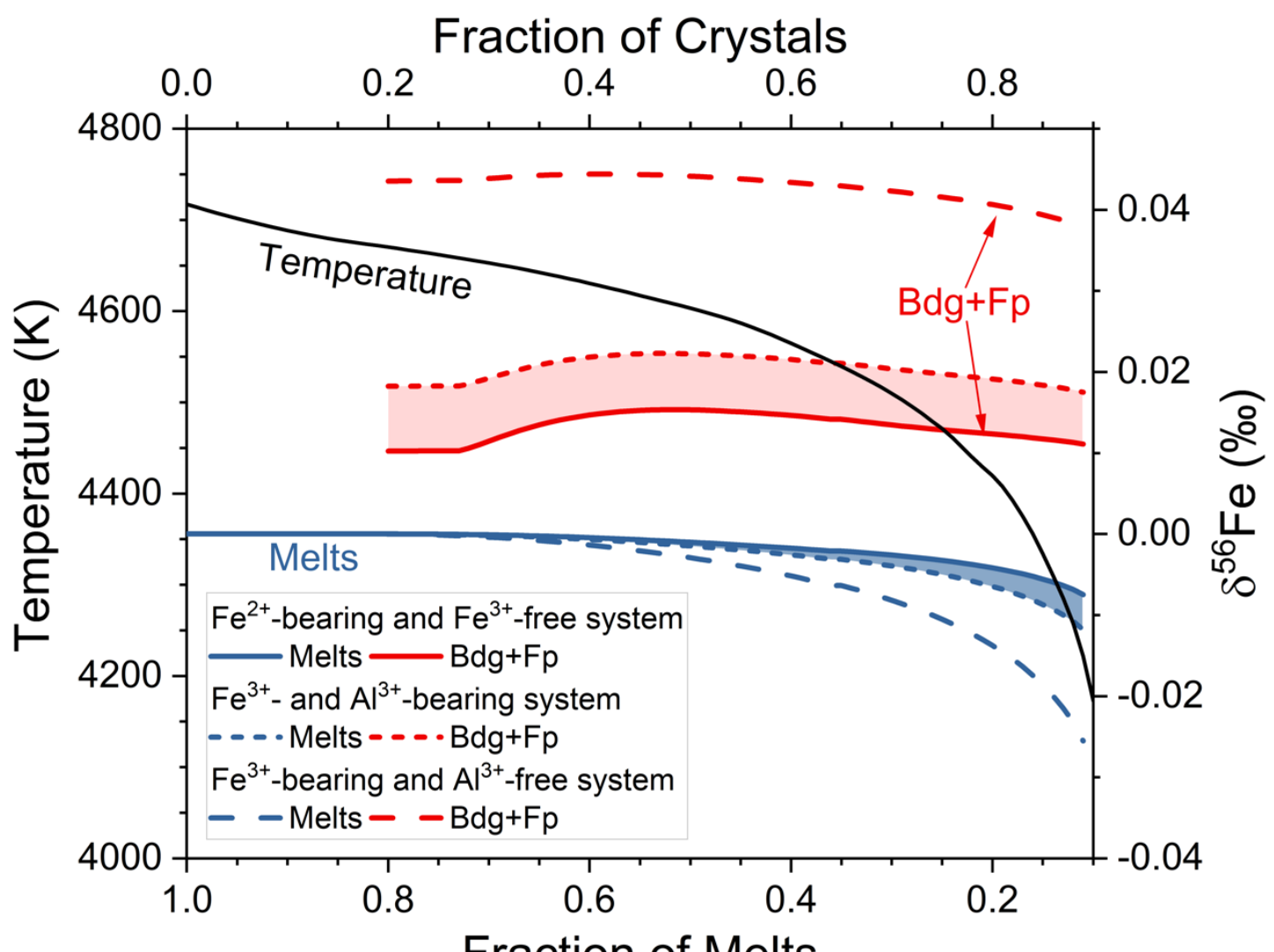

598 Figure 8. Equilibrium Fe isotope fractionation between solids and melts during magma ocean crystallization at $130 \mathrm{GPa}$. The modelling details were described in details in Yang et al. (2019).

600 Similarly, the initial $\delta^{56} \mathrm{Fe}$ of magma ocean is set as $0 \%$ and the solid crystallization sequence 601 was obtained from Boukaré et al. (2015). Red and blue lines represent $\delta^{56} \mathrm{Fe}$ of solids (Bdg+Fp) and melts, respectively. Solid, short dash, and dash lines refer to $\mathrm{Fe}^{2+}$-bearing and $\mathrm{Fe}^{3+}$-free,

$603 \mathrm{Fe}^{3+}$ - and $\mathrm{Al}^{3+}$-bearing, and $\mathrm{Fe}^{3+}$-bearing and $\mathrm{Al}^{3+}$-free systems, respectively. The $<F>$ of solids 604 and melts at $130 \mathrm{GPa}$ are used for modelling. Data sources: Bdg, DFT $+U$ calculations in this study; Fp, extrapolated to $130 \mathrm{GPa}$, Yang et al. (2019); melts, imitated by basaltic glass, extrapolated to $130 \mathrm{GPa}$ (Liu et al., 2017). The case for a pyrolitic composition, in which both $607 \mathrm{Fe}^{2+}$ and $\mathrm{Fe}^{3+}$ could be present but $\mathrm{Fe}^{3+}$ is not expected to occupy the Bdg B-site, can be represented by shade areas enclosed by solid and short dash lines.

\subsection{Fe isotope fractionation between core and mantle}

Mid-ocean ridge basalts (MORB) in the Earth were found to be enriched in heavy

612 Fe isotopes $\left({ }^{56} \mathrm{Fe} /{ }^{54} \mathrm{Fe}\right)$ by $\sim+0.1 \%$ relative to the chondrites (Teng et al., 2013), while

613 basalts from Mars and Vesta have Fe isotope compositions similar to the chondrites 
614 (Sossi et al., 2016; Elardo and Shahar, 2017). The elevated ${ }^{56} \mathrm{Fe} /{ }^{54} \mathrm{Fe}$ ratio in MORB 615 was thought to be caused by mantle partial melting (Teng et al., 2008; Dauphas et al., 616 2014), but this process can only induce an iron isotopic shift of $+0.023 \%$ (Dauphas et 617 al., 2014). Some other interpretations, including loss of light Fe isotopes during 618 vaporization and condensation (Poitrasson et al., 2004; Poitrasson, 2007), core 619 formation (Polyakov, 2009; Elardo and Shahar, 2017), have been proposed to enrich 620 Earth's mantle in heavy Fe isotopes. Some studies suggested that the Fe isotope 621 composition of mantle peridotites is close to that of chondrites (Poitrasson, 2007; 622 Craddock et al., 2013), while it has been argued that mantle peridotites may be slightly heavier ( $+0.05 \%$ ) than chondrites (Poitrasson et al., 2013; Sossi et al., 2016). It is not

624 well-known whether the Fe isotope composition of the primitive mantle has been 625 modified by core formation.

626 In order to check the effect of core formation on the Fe isotope composition of 627 bulk silicate Earth, previous studies have widely investigated the $\langle F>$ of metallic alloys 628 (Chen et al., 2014; Shahar et al., 2016; Liu et al., 2017; Chen et al., 2018) and basaltic 629 glass (Liu et al., 2017), which were used as analogues to metallic and silicate melts, 630 respectively. In addition, $\mathrm{Fe}^{2+}$-bearing $\mathrm{Bdg}$ was also used as the analogue to silicate 631 melt (Shahar et al., 2016). Here we also assume that the $\langle F\rangle$ of silicate melts could be 632 represented by those of $\mathrm{Bdg}$, as we find that $\mathrm{Fe}^{2+}$-bearing and $\mathrm{Fe}^{3+}$-free $\mathrm{Bdg}$ has similar $633<F>$ to the $\mathrm{Fe}^{2+}$-bearing basaltic glass at 40-60 GPa (Fig. 9). Our results show that Bdg 634 has relatively larger $\langle F>$ than metallic alloys and the $\langle F>$ difference between Bdg and 635 metallic alloys depends on their chemical compositions (Fig. 9). Using the high636 temperature approximation, we conclude that the equilibrium Fe isotope fractionation 637 between silicate and metallic melts is $\sim 0-0.04 \%$ under core-formation conditions for 638 the Earth ( 40-60 GPa and $3500 \mathrm{~K}$ ) (Li and Agee, 1996; Siebert et al., 2012; Fischer et 639 al., 2015). This implies that core formation can only shift the Fe isotope composition 640 of Earth's mantle by $0-0.04 \%$, which is not sufficient to account for the enrichment of 641 heavy Fe isotopes in MORB with the consideration of partial melting.

642 In contrast, heavy Fe isotopes might be enriched in the lowermost lower mantle 643 with respect to the adjacent liquid outer core, as low-spin Fe species likely to be present 644 in phases at the base of the mantle are expected to have high $\beta$-factors and 
645 corresponding force constants $\left\langle F>\right.$ (Fig. 9). At $P-T$ conditions near the $\mathrm{CMB}, \mathrm{Fe}^{2+}$ is 646 expected to adopt LS state in both solid and liquid FeO-MgO system (Mao et al., 2011; 647 Fu et al., 2018a; Yang et al., 2019); while $\mathrm{Fe}^{3+}$ in the octahedral site of both Bdg and 648 Ppv is expected to adopt LS state (Catalli et al., 2010; Yu et al., 2012; Liu et al., 2018). 649 At a representative $P-T$ condition near the CMB (130 GPa and $3000 \mathrm{~K})$, the calculated $650 \Delta^{56} \mathrm{Fe}_{\mathrm{Bdg}-\mathrm{core}}$ from the corresponding $<F>$ with $\mathrm{LS} \mathrm{Fe}^{3+}$ in the B-site of Bdg could range 651 from $+0.09 \%$ to $+0.12 \%$ for various outer core compositions, such as $\mathrm{Si}, \mathrm{S}$ and $\mathrm{C}$ (Fig. 652 9), if there is a chemical exchange and equilibration of solid mantle with outer 653 core. $\left(\mathrm{Fe}^{2+}, \mathrm{Mg}\right) \mathrm{SiO}_{3}-\mathrm{Ppv}$ was found to be enriched in heavy iron isotopes relative to 654 metallic iron with $\Delta^{56} \mathrm{Fe}_{\mathrm{Ppv} \text {-core }}$ of $\sim 0.1 \%$ at the $\mathrm{CMB}$ (Polyakov, 2009), and $\mathrm{Fe}^{3+}-$ 655 bearing Ppv should be more enriched in heavy iron isotopes. Meanwhile, $\Delta^{56} \mathrm{Fe}_{\mathrm{Fp} \text {-core }}$ 656 ranges from $+0.17 \%$ to $+0.20 \%$ for $\mathrm{CMB}$ regions with high concentrations of $\mathrm{LS} \mathrm{FeO}$, 657 such as some ultra-low velocity zones (Wicks et al., 2010; Fu et al., 2018a). These 658 fractionation factors suggest that $\mathrm{Fe}$ isotopes might be redistributed during the mantle659 core interaction and some local regions above the CMB could be enriched in heavy Fe 660 isotopes. However, whether such a Fe isotopic signature could be produced and 661 preserved or not also depends on the interaction pattern and the geodynamic mantle 662 convention (Lesher et al., 2020). 


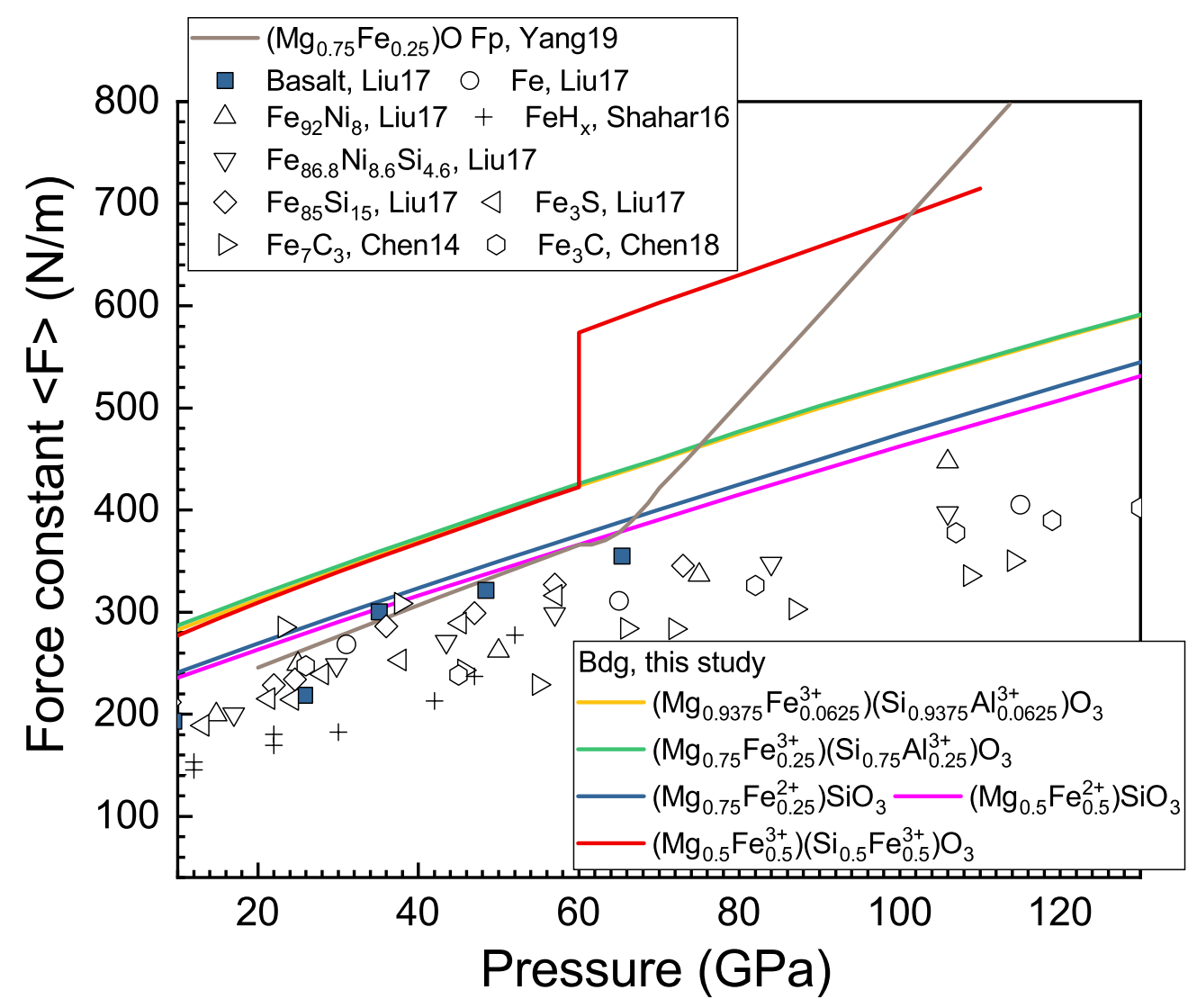

665 Figure 9. Comparison of force constants $\langle F>$ of Bdg computed in this work with previous 666 studies of $\mathrm{Fp}$ and $\mathrm{Fe} / \mathrm{Fe}$ alloys. At a given $P-T$ condition, $\mathrm{Fe}$ equilibrium isotopic fractionation 667 factor can be obtained by following $\Delta^{56} \mathrm{Fe}_{\mathrm{A}-\mathrm{B}}=2940\left(\left\langle F>_{\mathrm{A}^{-}}<F>_{\mathrm{B}}\right) / T^{2}\right.$. Experimental data sources: 668 Bdg, this study; $\quad\left(\mathrm{Mg}_{0.75} \mathrm{Fe}_{0.25}\right) \mathrm{O} \quad \mathrm{Fp}$, Yang et al. (2019); Basaltic 669 glass $\left(\mathrm{Na}_{0.036} \mathrm{Ca}_{0.220} \mathrm{Mg}_{0.493} \mathrm{Fe}_{0.115} \mathrm{Al}_{0.307} \mathrm{Ti}_{0.012} \mathrm{~K}_{0.002} \mathrm{Si}_{0.834} \mathrm{O}_{3}\right), \mathrm{Fe}, \mathrm{Fe}_{86.8} \mathrm{Ni}_{8.6} \mathrm{Si}_{4.6}, \mathrm{Fe}_{85} \mathrm{Si}_{15}, \mathrm{Fe}_{3} \mathrm{~S}$ : 670 Liu et al. (2017); $\mathrm{Fe}_{7} \mathrm{C}_{3}$ : Chen et al. (2014); $\mathrm{Fe}_{3} \mathrm{C}$ : Chen et al. (2018); FeHx: Shahar et al. (2016).

\section{Conclusion}

673 We have investigated the effects of site occupancies, chemical composition, spin 674 transition, and valence state on the reduced Fe partition function ratio ( $\beta$-factor) of $(\mathrm{Mg}$, $\left.675 \mathrm{Fe}^{2+}, \mathrm{Fe}^{3+}, \mathrm{Al}^{3+}\right)\left(\mathrm{Fe}^{3+}, \mathrm{Al}^{3+}, \mathrm{Si}\right) \mathrm{O}_{3} \mathrm{Bdg}$ under lower-mantle pressure-temperature 676 conditions by performing first-principles calculations and synergistic nuclear resonant 677 inelastic X-ray scattering measurements. The computational partial phonon density of 678 states of $\mathrm{Fe}^{3+}$ in $\left(\mathrm{Mg}_{0.5} \mathrm{Fe}^{3+}{ }_{0.5}\right)\left(\mathrm{Si}_{0.5} \mathrm{Fe}^{3+}{ }_{0.5}\right) \mathrm{O}_{3}$ bridgmanite agree well with experimental 679 measurements at high pressures. Our results reveal that $\mathrm{Fe}^{2+}$-bearing $\mathrm{Bdg}$ has the 680 smallest $\beta$-factor relative to other $\mathrm{Fe}^{3+}$-bearing species. Site occupancies for $\mathrm{Fe}^{3+}$ can 
681 have a significant effect on the $\beta$-factor of Bdg. Compared to the A-site $\mathrm{HS} \mathrm{Fe}^{3+}$, the B-

682 site $\mathrm{HS} \mathrm{Fe}^{3+}$ has a higher $\beta$-factor by $\sim 0.17 \%$ at $40 \mathrm{GPa}$ and $1000 \mathrm{~K}$. The spin transition 683 of $\mathrm{B}$-site $\mathrm{Fe}^{3+}$ in $\mathrm{Bdg}$ influences its $\beta$-factor more significantly than variations in valence 684 state and chemical composition, with an increase of $\sim+0.83 \%$ across the spin transition 685 at $1000 \mathrm{~K}$. This change would be diminished to $+0.09 \%$ along an expected geotherm 686 of the lower mantle. The variation of $\beta$-factors is mainly controlled by the Fe-O bond 687 lengths, and the shorter bond lengths correspond to higher bond strength and $\beta$-factors. 688 In addition, although the incorporation of $\mathrm{Al}^{3+}$ into the $\mathrm{Bdg} \mathrm{B}$-site results in a mild 689 effect on the $\beta$-factor of A-site $\mathrm{Fe}^{3+}$ when compared to $\left(\mathrm{Mg}_{0.5} \mathrm{Fe}^{3+}{ }_{0.5}\right)\left(\mathrm{Si}_{0.5} \mathrm{Fe}^{3+}{ }_{0.5}\right) \mathrm{O}_{3}$ $690 \mathrm{Bdg}$, the presence of $\mathrm{Al}$ in Earth's lower mantle would decrease the impact of B-site $691 \mathrm{Fe}^{3+}$ spin transition on the $\beta$-factor of Bdg by preventing $\mathrm{Fe}^{3+}$ from occupying the $\mathrm{B}-$ 692 site. Combined with previous data, our models demonstrate that $\mathrm{Fe}$ isotopic 693 fractionation between Fp and Bdg in most parts of the lower mantle would not be 694 significant, except the lowermost parts. The crystallization of the magma ocean is also 695 unlikely to have resulted in significant iron isotopic fractionation in any deep-mantle 696 reservoir. In contrast, under the conditions of the core-mantle boundary, low-spin Fe697 bearing mantle minerals could concentrate heavy Fe isotopes by up to $+0.20 \%$ through 698 core-mantle interaction.

\section{Acknowledgements}

W.Z. Wang and Z.Q. Wu acknowledge the Strategic Priority Research Program of 703 China (41721002, 41925017). J.F.L. acknowledges support from the Geophysics 704 Program of the National Science Foundation (EAR-1502594). S.M.D. also 705 acknowledges support from NSF CSEDI (EAR-1664332). NRIXS experiments used 706 resources of the Advanced Photon Source, a U.S. Department of Energy (DOE) Office 707 of Science User Facility operated for the DOE Office of Science by Argonne National 708 Laboratory under Contract No. DE-AC02-06CH11357. We are grateful to the 709 constructive comments from Paolo Sossi and the other two anonymous reviewers and 710 editorial handling by Mike Toplis and Jeffrey G. Catalano. 
712 Research Data

713 Relevant data is provided in Electronic Supplementary materials. 


\section{References}

Akahama Y. and Kawamura H. (2010) Pressure calibration of diamond anvil Raman gauge to 410 GPa. J. Phys. Conf. Ser. 215, 012195. Available at: http://stacks.iop.org/1742$6596 / 215 / \mathrm{i}=1 / \mathrm{a}=012195$ ?key=crossref.e13853a2cfe73464df62698f42525ac4.

Andrault D., Muñoz M., Pesce G., Cerantola V., Chumakov A., Kantor I., Pascarelli S., Rüffer R. and Hennet L. (2018) Large oxygen excess in the primitive mantle could be the source of the Great Oxygenation Event. Geochemical Perspect. Lett., 5-10. Available at: http://www.geochemicalperspectivesletters.org/article1801.

Anisimov V. I., Zaanen J. and Andersen O. K. (1991) Band theory and Mott insulators: Hubbard U instead of Stoner I. Phys. Rev. B 44, 943-954.

Armstrong K., Frost D. J., McCammon C. A., Rubie D. C. and Boffa Ballaran T. (2019) Deep magma ocean formation set the oxidation state of Earth's mantle. Science (80-. ). 365, 903-906.

Bigeleisen J. and Mayer M. G. (1947) Calculation of Equilibrium Constants for Isotopic Exchange Reactions. J. Chem. Phys. 15, 261. Available at: http://scitation.aip.org/content/aip/journal/jcp/15/5/10.1063/1.1746492.

Blanchard M., Dauphas N., Hu M. Y., Roskosz M., Alp E. E., Golden D. C., Sio C. K., Tissot F. L. H., Zhao J., Gao L., Morris R. V., Fornace M., Floris A., Lazzeri M. and Balan E. (2015) Reduced partition function ratios of iron and oxygen in goethite. Geochim. Cosmochim. Acta 151, 19-33. Available at: https://linkinghub.elsevier.com/retrieve/pii/S0016703714007157.

Boukaré C.-E., Ricard Y. and Fiquet G. (2015) Thermodynamics of the MgO-FeOSiO 2 system up to $140 \mathrm{GPa}$ : Application to the crystallization of Earth's magma ocean. J. Geophys. Res. Solid Earth 120, 6085-6101. Available at: http://doi.wiley.com/10.1002/2015JB011929.

Brown J. M. and McQueen R. G. (1986) Phase transitions, Grüneisen parameter, and elasticity for shocked iron between $77 \mathrm{GPa}$ and $400 \mathrm{GPa}$. J. Geophys. Res. Solid Earth 91, 7485-7494. Available at: http://doi.wiley.com/10.1029/JB091iB07p07485.

CANIL D. and O'NEILL H. S. C. (1996) Distribution of Ferric Iron in some UpperMantle Assemblages. J. Petrol. 37, 609-635. Available at: https://academic.oup.com/petrology/articlelookup/doi/10.1093/petrology/37.3.609.

Catalli K., Shim S. H., Prakapenka V. B., Zhao J. and Sturhahn W. (2010) X-ray diffraction and Mössbauer spectroscopy of Fe3+- bearing Mg-silicate postperovskite at 128-138 GPa. Am. Mineral. 95, 418-421.

Catalli Krystle, Shim S. H., Prakapenka V. B., Zhao J., Sturhahn W., Chow P., Xiao Y., Liu H., Cynn H. and Evans W. J. (2010) Spin state of ferric iron in MgSiO3 perovskite and its effect on elastic properties. Earth Planet. Sci. Lett. 289, 68-75. Available at: http://dx.doi.org/10.1016/j.epsl.2009.10.029. 
Chen B., Lai X., Li J., Liu J., Zhao J., Bi W., Ercan Alp E., Hu M. Y. and Xiao Y. (2018) Experimental constraints on the sound velocities of cementite $\mathrm{Fe} 3 \mathrm{C}$ to core pressures. Earth Planet. Sci. Lett. 494, 164-171. Available at: https://doi.org/10.1016/j.epsl.2018.05.002.

Chen B., Li Z., Zhang D., Liu J., Hu M. Y., Zhao J., Bi W., Alp E. E., Xiao Y., Chow P. and Li J. (2014) Hidden carbon in Earth's inner core revealed by shear softening in dense Fe 7 C 3. Proc. Natl. Acad. Sci. 111, 17755-17758. Available at: http://www.pnas.org/lookup/doi/10.1073/pnas.1411154111.

Cococcioni M. and de Gironcoli S. (2005) Linear response approach to the calculation of the effective interaction parameters in the LDA+U method. Phys. Rev. B 71, 035105. Available at: http://link.aps.org/doi/10.1103/PhysRevB.71.035105\%5Cnhttp://arxiv.org/abs/co nd-mat/0405160.

Craddock P. R. and Dauphas N. (2011) Iron Isotopic Compositions of Geological Reference Materials and Chondrites. Geostand. Geoanalytical Res. 35, 101-123. Available at: http://doi.wiley.com/10.1111/j.1751-908X.2010.00085.x.

Craddock P. R., Warren J. M. and Dauphas N. (2013) Abyssal peridotites reveal the near-chondritic Fe isotopic composition of the Earth. Earth Planet. Sci. Lett. 365, 63-76. Available at: http://dx.doi.org/10.1016/j.epsl.2013.01.011.

Dauphas N., Hu M. Y., Baker E. M., Hu J., Tissot F. L. H., Alp E. E., Roskosz M., Zhao J., Bi W., Liu J., Lin J.-F., Nie N. X. and Heard A. (2018) SciPhon: a data analysis software for nuclear resonant inelastic X-ray scattering with applications to Fe, Kr, Sn, Eu and Dy. J. Synchrotron Radiat. 25, 1581-1599.

Dauphas N., Roskosz M., Alp E. E., Golden D. C., Sio C. K., Tissot F. L. H., Hu M. Y., Zhao J., Gao L. and Morris R. V. (2012) A general moment NRIXS approach to the determination of equilibrium Fe isotopic fractionation factors: Application to goethite and jarosite. Geochim. Cosmochim. Acta 94, 254-275. Available at: http://linkinghub.elsevier.com/retrieve/pii/S0016703712003663.

Dauphas N., Roskosz M., Alp E. E., Neuville D. R., Hu M. Y., Sio C. K., Tissot F. L. H., Zhao J., Tissandier L., Médard E. and Cordier C. (2014) Magma redox and structural controls on iron isotope variations in Earth's mantle and crust. Earth Planet. Sci. Lett. 398, 127-140.

Dorfman S. M., Potapkin V., Lv M., Greenberg E., Kupenko I., Chumakov A. I., Bi W., Alp E. E., Liu J., Magrez A., Dutton S. E., Cava R. J., McCammon C. A. and Gillet P. (2020) Effects of composition and pressure on electronic states of iron in bridgmanite. Am. Mineral. 105, 1030-1039. Available at: https://pubs.geoscienceworld.org/msa/ammin/article/105/7/1030/587519/Effectsof-composition-and-pressure-on-electronic.

Elardo S. M. and Shahar A. (2017) Non-chondritic iron isotope ratios in planetary mantles as a result of core formation. Nat. Geosci. 10, 317-321.

Feng C., Qin T., Huang S., Wu Z. and Huang F. (2014) First-principles investigations of equilibrium calcium isotope fractionation between clinopyroxene and $\mathrm{Ca}-$ 
doped orthopyroxene. Geochim. Cosmochim. Acta 143, 132-142. Available at: http://dx.doi.org/10.1016/j.gca.2014.06.002.

Fischer R. A., Nakajima Y., Campbell A. J., Frost D. J., Harries D., Langenhorst F., Miyajima N., Pollok K. and Rubie D. C. (2015) High pressure metal-silicate partitioning of Ni, Co, V, Cr, Si, and O. Geochim. Cosmochim. Acta 167, 177194. Available at: https://linkinghub.elsevier.com/retrieve/pii/S0016703715004093.

Frost D. J., Liebske C., Langenhorst F., McCammon C. a, Tronnes R. G. and Rubie D. C. (2004) Experimental evidence for the existence of iron-rich metal in the Earth' s lower mantle. Nature 428, 409-412.

Frost D. J. and McCammon C. A. (2008) The Redox State of Earth's Mantle. Annu. Rev. Earth Planet. Sci. 36, 389-420. Available at: http://www.annualreviews.org/doi/10.1146/annurev.earth.36.031207.124322.

Fu S., Yang J., Zhang Y., Liu J., Greenberg E., Prakapenka V. B., Okuchi T. and Lin J. F. (2018a) Melting behavior of the lower-mantle ferropericlase across the spin crossover: Implication for the ultra-low velocity zones at the lowermost mantle. Earth Planet. Sci. Lett. 503, 1-9. Available at: https://doi.org/10.1016/j.eps1.2018.09.014.

Fu S., Yang J., Zhang Y., Okuchi T., McCammon C., Kim H. I., Lee S. K. and Lin J. F. (2018b) Abnormal Elasticity of Fe-Bearing Bridgmanite in the Earth's Lower Mantle. Geophys. Res. Lett. 45, 4725-4732.

Giannozzi P., Baroni S., Bonini N., Calandra M., Car R., Cavazzoni C., Ceresoli D., Chiarotti G. L., Cococcioni M., Dabo I., Dal Corso A., de Gironcoli S., Fabris S., Fratesi G., Gebauer R., Gerstmann U., Gougoussis C., Kokalj A., Lazzeri M., Martin-Samos L., Marzari N., Mauri F., Mazzarello R., Paolini S., Pasquarello A., Paulatto L., Sbraccia C., Scandolo S., Sclauzero G., Seitsonen A. P., Smogunov A., Umari P. and Wentzcovitch R. M. (2009) QUANTUM ESPRESSO: a modular and open-source software project for quantum simulations of materials. J. Phys. Condens. Matter 21, 395502. Available at: http://stacks.iop.org/0953$8984 / 21 / \mathrm{i}=39 / \mathrm{a}=395502$ ?key=crossref.c21336c286fa6d3db893262ae3f6e151.

Hsu H., Blaha P., Cococcioni M. and Wentzcovitch R. M. (2011) Spin-State Crossover and Hyperfine Interactions of Ferric Iron in MgSiO3 Perovskite. Phys. Rev. Lett. 106, 118501. Available at: https://link.aps.org/doi/10.1103/PhysRevLett.106.118501.

Hsu H., Umemoto K., Blaha P. and Wentzcovitch R. M. (2010) Spin states and hyperfine interactions of iron in $(\mathrm{Mg}, \mathrm{Fe}) \mathrm{SiO} 3$ perovskite under pressure. Earth Planet. Sci. Lett. 294, 19-26. Available at: https://linkinghub.elsevier.com/retrieve/pii/S0012821X10001330.

Huang F., Chen L., Wu Z. and Wang W. (2013) First-principles calculations of equilibrium $\mathrm{Mg}$ isotope fractionations between garnet, clinopyroxene, orthopyroxene, and olivine: Implications for Mg isotope thermometry. Earth 
Planet. Sci. Lett. 367, 61-70. Available at: http://dx.doi.org/10.1016/j.epsl.2013.02.025.

Huang F., Wu Z., Huang S. and Wu F. (2014) First-principles calculations of equilibrium silicon isotope fractionation among mantle minerals. Geochim. Cosmochim. Acta 140, 509-520. Available at: http://dx.doi.org/10.1016/j.gca.2014.05.035.

Irifune T. and Ringwood A. E. (1987) Phase transformations in a harzburgite composition to $26 \mathrm{GPa}$ : implications for dynamical behaviour of the subducting slab. Earth Planet. Sci. Lett. 86, 365-376. Available at: https://linkinghub.elsevier.com/retrieve/pii/0012821X87902330.

Irifune T., Shinmei T., McCammon C. A., Miyajima N., Rubie D. C. and Frost D. J. (2010) Iron Partitioning and Density Changes of Pyrolite in Earth's Lower Mantle. Science (80-. ). 327, 193-195. Available at: http://www.sciencemag.org/lookup/doi/10.1126/science.1181443.

Kowalski P. M., Wunder B. and Jahn S. (2013) Ab initio prediction of equilibrium boron isotope fractionation between minerals and aqueous fluids at high $\mathrm{P}$ and $\mathrm{T}$. Geochim. Cosmochim. Acta 101, 285-301. Available at: http://dx.doi.org/10.1016/j.gca.2012.10.007.

Lesher C. E., Dannberg J., Barfod G. H., Bennett N. R., Glessner J. J. G., Lacks D. J. and Brenan J. M. (2020) Iron isotope fractionation at the core-mantle boundary by thermodiffusion. Nat. Geosci. 13, 382-386. Available at: http://dx.doi.org/10.1038/s41561-020-0560-y.

Li J. and Agee C. B. (1996) Geochemistry of mantle-core differentiation at high pressure. Nature 381, 686-689. Available at: http://www.nature.com/articles/381686a0.

Li J., Sturhahn W., Jackson J. M., Struzhkin V. V., Lin J. F., Zhao J., Mao H. K. and Shen G. (2006) Pressure effect on the electronic structure of iron in $(\mathrm{Mg}, \mathrm{Fe})(\mathrm{Si}, \mathrm{Al}) \mathrm{O} 3$ perovskite: a combined synchrotron Mössbauer and X-ray emission spectroscopy study up to $100 \mathrm{GPa}$. Phys. Chem. Miner. 33, 575-585. Available at: http://link.springer.com/10.1007/s00269-006-0105-y.

Lin J.-F., Speziale S., Mao Z. and Marquardt H. (2013) EFFECTS OF THE ELECTRONIC SPIN TRANSITIONS OF IRON IN LOWER MANTLE MINERALS: IMPLICATIONS FOR DEEP MANTLE GEOPHYSICS AND GEOCHEMISTRY. Rev. Geophys. 51, 244-275. Available at: http://doi.wiley.com/10.1002/rog.20010.

Liu J., Dauphas N., Roskosz M., Hu M. Y., Yang H., Bi W., Zhao J., Alp E. E., Hu J. Y. and Lin J. F. (2017) Iron isotopic fractionation between silicate mantle and metallic core at high pressure. Nat. Commun. 8, ncomms14377.

Liu J., Dorfman S. M., Zhu F., Li J., Wang Y., Zhang D., Xiao Y., Bi W. and Ercan Alp E. (2018) Valence and spin states of iron are invisible in Earth's lower mantle. Nat. Commun. 9, 1-9. Available at: http://dx.doi.org/10.1038/s41467018-03671-5. 
Liu J., Mysen B., Fei Y. and Li J. (2015) Recoil-free fractions of iron in aluminous bridgmanite from temperature-dependent Mössbauer spectra. Am. Mineral. 100, 1978-1984. Available at: https://pubs.geoscienceworld.org/ammin/article/100/89/1978-1984/106340.

Mao H. K., Xu J. and Bell P. M. (1986) Calibration of the ruby pressure gauge to 800 kbar under quasi-hydrostatic conditions. J. Geophys. Res. 91, 4673. Available at: http://doi.wiley.com/10.1029/JB091iB05p04673.

Mao Z., Lin J.-F., Liu J. and Prakapenka V. B. (2011) Thermal equation of state of lower-mantle ferropericlase across the spin crossover. Geophys. Res. Lett. 38, n/a-n/a. Available at: http://doi.wiley.com/10.1029/2011GL049915.

Mao Z., Lin J. F., Yang J., Inoue T. and Prakapenka V. B. (2015) Effects of the Fe3+ spin transition on the equation of state of bridgmanite. Geophys. Res. Lett. 42, 4335-4342.

Marquardt H., Speziale S., Reichmann H. J., Frost D. J., Schilling F. R. and Garnero E. J. (2009) Elastic Shear Anisotropy of Ferropericlase in Earth's Lower Mantle. Science (80-. ). 324, 224-226. Available at: http://www.sciencemag.org/cgi/doi/10.1126/science.1169365.

McCammon C. (1997) Perovskite as a possible sink for ferric iron in the lower mantle. Nature 387, 694-696. Available at: http://www.nature.com/articles/42685.

McDonough W. F. and Sun S. -s. (1995) The composition of the Earth. Chem. Geol. 120, 223-253. Available at: http://linkinghub.elsevier.com/retrieve/pii/0009254194001404.

Núñez-Valdez M., Wu Z., Yu Y. G. and Wentzcovitch R. M. (2013) Thermal elasticity of (Fe x , Mg 1- x ) $2 \mathrm{SiO} 4$ olivine and wadsleyite. Geophys. Res. Lett. 40, 290-294. Available at: http://doi.wiley.com/10.1002/grl.50131.

Núñez Valdez M., Wu Z., Yu Y. G., Revenaugh J. and Wentzcovitch R. M. (2012) Thermoelastic properties of ringwoodite (Fex,Mg1-x)2SiO4: Its relationship to the 520km seismic discontinuity. Earth Planet. Sci. Lett. 351-352, 115-122.

Poitrasson F. (2007) Does planetary differentiation really fractionate iron isotopes? Earth Planet. Sci. Lett. 256, 484-492.

Poitrasson F., Delpech G. and Grégoire M. (2013) On the iron isotope heterogeneity of lithospheric mantle xenoliths: implications for mantle metasomatism, the origin of basalts and the iron isotope composition of the Earth. Contrib. to Mineral. Petrol. 165, 1243-1258. Available at: http://link.springer.com/10.1007/s00410-013-0856-7.

Poitrasson F., Halliday A. N., Lee D. C., Levasseur S. and Teutsch N. (2004) Iron isotope differences between Earth, Moon, Mars and Vesta as possible records of contrasted accretion mechanisms. Earth Planet. Sci. Lett. 223, 253-266.

Poitrasson F., Roskosz M. and Corgne A. (2009) No iron isotope fractionation between molten alloys and silicate melt to $2000{ }^{\circ} \mathrm{C}$ and $7.7 \mathrm{GPa}$ : Experimental evidence and implications for planetary differentiation and accretion. Earth 
Planet. Sci. Lett. 278, 376-385. Available at: http://dx.doi.org/10.1016/j.eps1.2008.12.025.

Polyakov V. B. (2009) Equilibrium Iron Isotope Fractionation at Core-Mantle Boundary Conditions. Science (80-. ). 323, 912-914. Available at: http://www.sciencemag.org/cgi/doi/10.1126/science.1166329.

Qian W., Wang W., Zou F. and Wu Z. (2018) Elasticity of Orthoenstatite at High Pressure and Temperature: Implications for the Origin of Low V P / V S Zones in the Mantle Wedge. Geophys. Res. Lett. 45, 665-673. Available at: http://doi.wiley.com/10.1002/2017GL075647.

Rubie D. C., Nimmo F. and Melosh H. J. (2015) Formation of the Earth's Core. In Treatise on Geophysics Elsevier. pp. 43-79. Available at: http://linkinghub.elsevier.com/retrieve/pii/B9780444538024001548.

Rustad J. R. and Yin Q.-Z. (2009) Iron isotope fractionation in the Earth's lower mantle. Nat. Geosci. 2, 514-518. Available at: http://dx.doi.org/10.1038/ngeo546.

Schauble E. A. (2011) First-principles estimates of equilibrium magnesium isotope fractionation in silicate, oxide, carbonate and hexaaquamagnesium(2+) crystals. Geochim. Cosmochim. Acta 75, 844-869. Available at: http://linkinghub.elsevier.com/retrieve/pii/S0016703710006332.

Shahar A., Schauble E. A., Caracas R., Gleason A. E., Reagan M. M., Xiao Y., Shu J. and Mao W. (2016) Pressure-dependent isotopic composition of iron alloys. Science (80-. ). 352, 580-582.

Shim S.-H., Grocholski B., Ye Y., Alp E. E., Xu S., Morgan D., Meng Y. and Prakapenka V. B. (2017) Stability of ferrous-iron-rich bridgmanite under reducing midmantle conditions. Proc. Natl. Acad. Sci. 114, 6468-6473. Available at: http://www.pnas.org/lookup/doi/10.1073/pnas.1614036114.

Shukla G. and Wentzcovitch R. M. (2016) Spin crossover in $(\mathrm{Mg}, \mathrm{Fe} 3+)(\mathrm{Si}, \mathrm{Fe} 3+) \mathrm{O} 3$ bridgmanite: Effects of disorder, iron concentration, and temperature. Phys. Earth Planet. Inter. 260, 53-61. Available at: http://dx.doi.org/10.1016/j.pepi.2016.09.003.

Shukla G., Wu Z., Hsu H., Floris A., Cococcioni M. and Wentzcovitch R. M. (2015) Thermoelasticity of Fe 2+ -bearing bridgmanite. Geophys. Res. Lett. 42, 17411749. Available at: http://doi.wiley.com/10.1002/2014GL062888.

Siebert J., Badro J., Antonangeli D. and Ryerson F. J. (2012) Metal-silicate partitioning of $\mathrm{Ni}$ and $\mathrm{Co}$ in a deep magma ocean. Earth Planet. Sci. Lett. 321322, 189-197. Available at: http://dx.doi.org/10.1016/j.epsl.2012.01.013.

Sossi P. A., Halverson G. P., Nebel O. and Eggins S. M. (2015) Combined Separation of $\mathrm{Cu}, \mathrm{Fe}$ and $\mathrm{Zn}$ from Rock Matrices and Improved Analytical Protocols for Stable Isotope Determination. Geostand. Geoanalytical Res. 39, 129-149. Available at: http://doi.wiley.com/10.1111/j.1751-908X.2014.00298.x. reservoirs. Earth Planet. Sci. Lett. 452, 295-308. Available at: 

http://dx.doi.org/10.1016/j.epsl.2016.07.032.

Teng F.-Z., Dauphas N. and Helz R. T. (2008) Iron Isotope Fractionation During Magmatic Differentiation in Kilauea Iki Lava Lake. Science (80-. ). 320, 1620 1622. Available at: http://www.sciencemag.org/cgi/doi/10.1126/science.1157166.

Teng F.-Z., Dauphas N. and Watkins J. M. (2017) Non-Traditional Stable Isotopes: Retrospective and Prospective. Rev. Mineral. Geochemistry 82, 1 LP - 26. Available at: http://rimg.geoscienceworld.org/content/82/1/1.abstract.

Teng F. Z., Dauphas N., Huang S. and Marty B. (2013) Iron isotopic systematics of oceanic basalts. Geochim. Cosmochim. Acta 107, 12-26. Available at: http://dx.doi.org/10.1016/j.gca.2012.12.027.

Togo A. and Tanaka I. (2015) First principles phonon calculations in materials science. Scr. Mater. 108, 1-5. Available at: http://dx.doi.org/10.1016/j.scriptamat.2015.07.021.

Vanderbilt D. (1990) Soft self-consistent pseudopotentials in a generalized eigenvalue formalism. Phys. Rev. B 41, 7892-7895. Available at: http://link.aps.org/doi/10.1103/PhysRevB.41.7892.

Wang W., Qin T., Zhou C., Huang S., Wu Z. and Huang F. (2017a) Concentration effect on equilibrium fractionation of $\mathrm{Mg}-\mathrm{Ca}$ isotopes in carbonate minerals: Insights from first-principles calculations. Geochim. Cosmochim. Acta 208, 185197. Available at: http://dx.doi.org/10.1016/j.gca.2017.03.023.

Wang W., Walter M. J., Peng Y., Redfern S. and Wu Z. (2019a) Constraining olivine abundance and water content of the mantle at the $410-\mathrm{km}$ discontinuity from the elasticity of olivine and wadsleyite. Earth Planet. Sci. Lett. 519, 1-11. Available at: https://doi.org/10.1016/j.eps1.2019.04.018.

Wang W. and Wu Z. (2018) Elasticity of Corundum at High Pressures and Temperatures: Implications for Pyrope Decomposition and Al-Content Effect on Elastic Properties of Bridgmanite. J. Geophys. Res. Solid Earth 123, 1201-1216. Available at: http://doi.wiley.com/10.1002/2017JB015088.

Wang W., Zhou C., Liu Y., Wu Z. and Huang F. (2019b) Equilibrium Mg isotope fractionation among aqueous $\mathrm{Mg} 2+$, carbonates, brucite and lizardite: Insights from first-principles molecular dynamics simulations. Geochim. Cosmochim. Acta 250, 117-129. Available at: https://doi.org/10.1016/j.gca.2019.01.042.

Wang W., Zhou C., Qin T., Kang J., Huang S., Wu Z. and Huang F. (2017b) Effect of $\mathrm{Ca}$ content on equilibrium $\mathrm{Ca}$ isotope fractionation between orthopyroxene and clinopyroxene. Geochim. Cosmochim. Acta 219, 44-56. Available at: http://dx.doi.org/10.1016/j.gca.2017.09.022.

Wang X., Tsuchiya T. and Hase A. (2015) Computational support for a pyrolitic lower mantle containing ferric iron. Nat. Geosci. 8, 556-559. Available at: http://www.nature.com/doifinder/10.1038/ngeo2458.

Wicks J. K., Jackson J. M. and Sturhahn W. (2010) Very low sound velocities in ironrich $(\mathrm{Mg}, \mathrm{Fe}) \mathrm{O}$ : Implications for the core-mantle boundary region. Geophys. Res. 
Lett. 37, n/a-n/a. Available at: http://doi.wiley.com/10.1029/2010GL043689.

Woodland A. B., Kornprobst J. and Tabit A. (2006) Ferric iron in orogenic lherzolite massifs and controls of oxygen fugacity in the upper mantle. Lithos 89, 222-241.

Wu Z. (2016) Velocity structure and composition of the lower mantle with spin crossover in ferropericlase. J. Geophys. Res. Solid Earth 121, 2304-2314. Available at: http://doi.wiley.com/10.1002/2015JB012667.

Wu Z., Huang F. and Huang S. (2015a) Isotope fractionation induced by phase transformation: First-principles investigation for Mg2SiO4. Earth Planet. Sci. Lett. 409, 339-347. Available at: http://dx.doi.org/10.1016/j.epsl.2014.11.004.

Wu Z., Huang F. and Huang S. (2015b) Isotope fractionation induced by phase transformation: First-principles investigation for Mg2SiO4. Earth Planet. Sci. Lett. 409, 339-347.

Wu Z., Justo J. F. and Wentzcovitch R. M. (2013) Elastic Anomalies in a SpinCrossover System: Ferropericlase at Lower Mantle Conditions. Phys. Rev. Lett. 110, 228501. Available at: http://link.aps.org/doi/10.1103/PhysRevLett.110.228501.

Yang H., Lin J. F., Hu M. Y., Roskosz M., Bi W., Zhao J., Alp E. E., Liu Jin, Liu Jiachao, Wentzowitch R. M., Okuchi T. and Dauphas N. (2019) Iron isotopic fractionation in mineral phases from Earth's lower mantle: Did terrestrial magma ocean crystallization fractionate iron isotopes? Earth Planet. Sci. Lett. 506, 113122. Available at: https://doi.org/10.1016/j.epsl.2018.10.034.

Yu Y. G., Hsu H., Cococcioni M. and Wentzcovitch R. M. (2012) Spin states and hyperfine interactions of iron incorporated in MgSiO3post-perovskite. Earth Planet. Sci. Lett. 331-332, 1-7.

Zhang S., Cottaar S., Liu T., Stackhouse S. and Militzer B. (2016) High-pressure, temperature elasticity of $\mathrm{Fe}$ - and Al-bearing $\mathrm{MgSiO} 3$ : Implications for the Earth's lower mantle. Earth Planet. Sci. Lett. 434, 264-273. Available at: http://dx.doi.org/10.1016/j.eps1.2015.11.030. 